\title{
A Comparison of Visual Response Properties in the Lateral Geniculate Nucleus and Primary Visual Cortex of Awake and Anesthetized Mice
}

\author{
@Séverine Durand,* Ramakrishnan Iyer,* Kenji Mizuseki, @Saskia de Vries, Stefan Mihalas, and R. Clay Reid \\ Allen Institute for Brain Science, Seattle, Washington 98103
}

The cerebral cortex of the mouse has become one of the most important systems for studying information processing and the neural correlates of behavior. Multiple studies have examined the first stages of visual cortical processing: primary visual cortex (V1) and its thalamic inputs from the dorsal lateral geniculate nucleus (dLGN), but more rarely in the lateral posterior nucleus (LP) in mice. Multiple single-unit surveys of dLGN and V1, both with electrophysiology and two-photon calcium imaging, have described receptive fields in anesthetized animals. Increasingly, awake animals are being used in physiological studies, so it is important to compare neuronal responses between awake and anesthetized state. We have performed a comprehensive survey of spatial and temporal response properties in V1, dLGN, and lateral posterior nucleus of both anesthetized and awake animals, using a common set of stimuli: drifting sine-wave gratings spanning a broad range of spatial and temporal parameters, and sparse noise stimuli consisting of flashed light and dark squares. Most qualitative receptive field parameters were found to be unchanged between the two states, such as most aspects of spatial processing, but there were significant differences in several parameters, most notably in temporal processing. Compared with anesthetized animals, the temporal frequency that evoked the peak response was shifted toward higher values in the dLGN of awake mice and responses were more sustained. Further, the peak response to a flashed stimulus was earlier in all three areas. Overall, however, receptive field properties in the anesthetized animal remain a good model for those in the awake animal.

Key words: anesthesia; LGN; LP; mouse; visual cortex

Significance Statement

The primary visual cortex (V1) of the mouse and its inputs from visual thalamus (dLGN), have become a dominant model for studying information processing in the brain. Early surveys of visual response properties (receptive fields) were performed in anesthetized animals. Although most recent studies of $\mathrm{V} 1$ have been performed in awake animals to examine links between vision and behavior, there have been few comprehensive studies of receptive field properties in the awake mouse, especially in dLGN and lateral posterior nucleus. We have performed a comparative survey of receptive fields in dLGN, lateral posterior nucleus, and V1 in anesthetized and awake mice. We found multiple differences in processing of time-varying stimuli, whereas the spatial aspects of receptive fields remain comparatively unchanged.

\section{Introduction}

The early stages of visual cortical processing are perhaps the beststudied aspects of cortical function. In cats and monkeys, the

\footnotetext{
Received May 30, 2016; revised Aug. 23, 2016; accepted Sept. 12, 2016.

Author contributions:S.D. and R.C.R. designed research;S.D. performed research;S.D., R.I., K.M., S.d.V., and S.M. analyzed data; S.D., R.I., and R.C.R. wrote the paper.

This work was supported by the Allen Institute for Brain Science and National Eye Institute Award EY018742. The contents are solely the responsibility of the authors and do not necessarily represent the official views of the National Institutes of Health and National Eye Institute. We thank the many staff members of the Allen Institute and especially the In Vivo Sciences team for surgeries; Derric Williams for technical support and programming; the Imaging Team and Naveen Ouellette for expert assistance; and Allen Institute founders Paul G. Allen and Jody Allen for their vision, encouragement, and support.

The authors declare no competing financial interests.

*S.D. and R.I. contributed equally to this study.
}

primary visual cortex (V1) and its thalamic afferents from the lateral geniculate nucleus (dLGN) have been the subject of hundreds of single-unit studies of visual receptive fields (RFs) in both anesthetized (Hubel and Wiesel, 1959, 1960, 1962) and awake animals (Hubel, 1958; Jasper et al., 1960). In the recent years, the mouse has become perhaps the dominant species in the study of V1 (Dräger, 1975; Mangini and Pearlman, 1980; Niell and Stryker, 2008; Liu et al., 2009; Gao et al., 2010; Kerlin et al., 2010; Ma et al., 2010; Niell and Stryker, 2010; Smith and Häusser, 2010;

Correspondence should be addressed to Dr. R. Clay Reid, Allen Institute for Brain Science, 551 North 34th Street, Seattle, WA 98103. E-mail: clayr@alleninstitute.org.

DOI:10.1523/JNEUROSCI.1741-16.2016

Copyright $\odot 2016$ the authors $\quad 0270-6474 / 16 / 3612144-13 \$ 15.00 / 0$ 
Andermann et al., 2011; Bonin et al., 2011; Piscopo et al., 2013), primarily because of its easy availability, its suitability for imaging studies, and the access to genetic tools that facilitate new molecular, anatomical, and physiological approaches to studying the brain. Surveys of V1 RF properties in the awake mouse so far have primarily used two-photon calcium imaging in the superficial layers (Liu et al., 2009; Ma et al., 2010; Smith and Häusser, 2010; Andermann et al., 2011) and layer 5 (Glickfeld et al., 2013). These studies found that most RF properties seen in anesthetized animals are largely similar in awake mice, particularly the spatial RF properties. There have been far fewer electrophysiology RF surveys of visual response properties in the dLGN and lateral posterior nucleus (LP), and these have been performed only in the anesthetized mice (Grubb and Thompson, 2003; Piscopo et al., 2013; Roth et al., 2016).

The goal of this study was to perform a comprehensive RF study facilitating comparisons between the visual response of neurons in the dLGN, LP, and V1 of both anesthetized and awake mice. We used a common set of visual stimuli: drifting sine-wave gratings spanning a broad range of spatial and temporal parameters, and sparse noise stimuli consisting of flashed light and dark squares. Most simply, this allowed for the comparisons between many studies that typically characterize responses in one area and in one state, either anesthetized or awake. Overall, we found qualitative similarity between responses in both states. Certain temporal aspects of responses differed, however, the time to peak response, the sustained time course triggered by flashed stimuli, and the preferred temporal frequency of drifting sinusoidal gratings.

\section{Materials and Methods}

Mice were maintained in the Allen Institute for Brain Science's animal facility and used in accordance to the protocol approved by Allen Institute for Brain Science's Institutional Animal Care and Use Committees.

\section{Extracellular multisite electrophysiology}

Electrophysiological recordings were performed in the left hemisphere of adult $\mathrm{C} 57 \mathrm{Bl} / 6$ mice (2-6 months, males). We performed experiments in awake $(n=17)$ and anesthetized mice $(n=8)$. In both cases, mice were first implanted, using aseptic conditions, with a metallic headplate under anesthesia with isoflurane (3\%-5\% induction and $1.5 \%$ maintenance, $100 \% \mathrm{O}_{2}$ ) and ketamine/xylazine $(70 \mathrm{mg} / \mathrm{kg}$, i.p.). Body temperature was maintained at $37.5^{\circ} \mathrm{C}$. After scalp incision and cleaning of the skull, a headplate was placed and secured by Vetbond (Webster Veterinary) and Metabond (Parkell). The headplate with a circular well over dLGN and cortex provides a secure way to stabilize the head and allows easy access to the skull. Finally, we sealed the skull surface with a thin layer of transparent Metabond and filled the well of the headplate with Kwik Cast (WPI) until the day before the experiment, 3-8 weeks later.

The day before recording, under aseptic conditions with anesthesia (as above), we performed two craniotomies: one over the dLGN/LP and one over V1 recording sites. We used two small craniotomies instead of a large one to reduce brain movement. The craniotomy above $\mathrm{dLGN} / \mathrm{LP}$ was $1 \times 1$ $\mathrm{mm}$ (centered at $2.2 \mathrm{~mm}$ lateral and $2.3 \mathrm{~mm}$ posterior to bregma); the second was as small as possible $(\sim 0.5 \times 0.5 \mathrm{~mm})$ above the monocular portion of V1 (2.5 mm lateral to lambda). The multishank dLGN electrodes required a durotomy. We also made two burr holes in the contralateral skull (one over frontal cortex and the other caudal over the cerebellum) used to secure the screws for reference and ground of the electrodes. Finally, after covering the brain with a small amount of sterile ACSF, the exposed skull was sealed with Kwik Cast, as in the first surgery.

To allow recovery from anesthesia and surgery, we performed the experiment the next day. We either kept the mice awake or anesthetized them with urethane $(1.2-1.5 \mathrm{~g} / \mathrm{kg}$, i.p.). Awake mice went directly into the recording setup. The headplate was clamped for stability while the animal was free to run or remain still on a freely rotating disk. If the mouse was anesthetized, we started by giving dexamethasone to avoid brain inflammation $(2 \mathrm{mg} / \mathrm{kg}$, s.c.) and atropine to keep the respiratory tract clear $(0.3 \mathrm{mg} / \mathrm{kg}$, i.p.). Then, it was head-clamped and placed on a heating pad with feedback control (ATC 1000, WPI), on a static disk. Body temperature was maintained at $37.5^{\circ} \mathrm{C}$.

For both awake and anesthetized recordings, the Kwik Cast was removed and the exposed cortex and skull were covered with $1 \%$ agarose in saline to prevent drying and to help maintain mechanical stability. Electrodes were dipped in DiI allowing post hoc visualization of the electrode's path and placed near the brain surface above dLGN and V1. The dLGN electrodes were either a Neuronexus Buzsáki32 (32 channels with 4 shanks) or a Buzsáki64 (64 channels and 6 shanks). The electrode was advanced vertically to a depth $2700-2900 \mu \mathrm{m}$ using a Kopf microdrive. V1 electrodes were either a Buzsáki32 (4 shanks) or an Edge32 (A1x32Edge-5 mm-20-177). The electrode was advanced at a 35 deg angle to a depth $800-1000 \mu \mathrm{m}$ with a Sutter Microdrive (Sutter Instrument MPC 200). The dLGN could be identified by the rapid firing of spikes evoked by bright flashes over a black background. We stopped advancing when we reached a point where most recording sites had units that responded to the flashes. On multiple occasions, the dLGN was missed and the electrode was instead placed in LP, as confirmed histologically, where visual response to flashes is present but more sluggish than in dLGN. To improve the stability of recorded units, we allowed $20 \mathrm{~min}$ for the electrodes to settle. In anesthetized mice, the eyes were covered with a thin layer of a long-lasting lubricating and moisturizing agent (Z-drop) to prevent drying. Experiments length was from 5 to $6 \mathrm{~h}$.

After the recordings, the mice were perfused with $4 \%$ PFA (after induction with $5 \%$ isoflurane and $1 \mathrm{~L} / \mathrm{min}$ of $\mathrm{O}_{2}$ ). The brains were preserved in $4 \%$ PFA, rinsed with $1 \times$ PBS the next morning, and stored at $4^{\circ} \mathrm{C}$ in PBS. We cut coronal or sagittal $100 \mu \mathrm{m}$ sections with a vibratome. The sections were mounted using VectaShield with DAPI (Vector Laboratories) and imaged on Olympus VS-110 120 with a magnification objective of $10 \times$ to reconstruct electrodes path in V1, dLGN, and LP (see Fig. 1). From the bottom of the DiI staining, we estimated where the tip of the electrode was positioned. For 20 of 25 experiments, the laminar location of cortical neurons was determined by comparing the location of recording sites relative to the tip with the laminar boundaries from the DAPI staining. The mean depth for each layer was $125.62 \pm 9.77$ (layer 1), $221 \pm 11.32$ (layer 2/3), $140.2 \pm 6.11$ (layer 4), $245.2 \pm 9.27$ (layer 5), and $210.2 \pm 9.05 \mu \mathrm{m}$ (layer 6 ). For the remaining cortical recordings, no laminar assignment was made. For 20 of 25 thalamic recordings, the Allen Mouse Brain Atlas (Lein et al., 2007) was used to confirm whether recordings were from dLGN or LP. The remaining 5 cases had RFs with the characteristics of histologically confirmed dLGN recordings and were thus classified as dLGN.

\section{Data acquisition}

Neurophysiological signals were amplified $(\times 400)$, bandpass filtered $(\sim 0.3$ $\mathrm{Hz}$ to $10 \mathrm{kHz}$ ), and acquired continuously at $20 \mathrm{kHz}$ at 16-bit resolution using an Amplipex system (Amplipex). The spike sorting procedure was described in detail previously (Mizuseki et al., 2009). In brief, extracellular action potentials were extracted from the recorded broadband signal after high pass filtering $(>800 \mathrm{~Hz})$ by a threshold crossing-based algorithm. Based on principal component analysis, the individual spikes were automatically clustered into groups using the KlustaKwik program (Harris et al., 2000), followed by manual adjustment of the clusters using the Klusters software package (http://klusters.sourceforge.net) (Hazan et al., 2006). Only units with clear refractory periods and well-defined cluster boundaries were included in the analyses (Harris et al., 2000).

\section{Visual stimuli}

Stimuli were generated in Python, using the Psychopy toolbox (Peirce, 2007), and were shown on an Asus PB238 screen $(1920 \times 1080$ pixels, $51 \mathrm{~cm}$ wide, $60 \mathrm{~Hz}$ refresh rate) adjusted with a flexible arm to be $45^{\circ}$ from the anteroposterior axis, $11 \mathrm{~cm}$ from the mouse's eye, thus subtending $133^{\circ}$ of visual field. The monitor was gammacorrected to linearize luminance.

We first hand-mapped the units to ensure that the RFs were on the screen, followed by brief full-field flashes $(50 \mathrm{~ms})$ to test the overall 
responsiveness in V1, dLGN, and LP. After ascertaining that there were multiple responsive cells, we began a protocol using a set of stimuli designed to inform us about the visual response properties in V1, dLGN, and LP. All stimuli extended over the full screen.

Gratings. To ensure a thorough exploration of neuronal response, which have been shown to span a broad range of spatial and temporal scales (Niell and Stryker, 2008; Andermann et al., 2011; Piscopo et al., 2013), we presented an extensive matrix of stimuli consisting of drifting gratings that required hours of presentation. The first stimulus set consisted of eight directions ( 4 orientations) spaced uniformly between 0 deg and $360 \mathrm{deg}$, six spatial frequencies $(0.02,0.04,0.08,0.16,0.32$ and 0.64 cycles per degree), and five temporal frequencies $(1,2,4,8,15 \mathrm{~Hz})$ with contrast fixed at $80 \%$. A second drifting grating stimulus was used to determine contrast response properties. This stimulus consisted of 3 or 4 orientations and $6-8$ contrasts $(10 \%, 20 \%, 40 \%, 60 \%, 80 \%$, and $100 \%$ or $1 \%, 5 \%, 10 \%, 20 \%, 40 \%, 60 \%, 80 \%$, and $100 \%)$, with spatial frequency fixed at $0.05 \mathrm{cpd}$ and temporal frequency $3 \mathrm{~Hz}$. For both stimulus sets, gratings were presented for $3 \mathrm{~s}$ with $1 \mathrm{~s}$ of mean luminance gray between successive gratings. Blank (mean gray) stimuli were randomly interleaved to measure the spontaneous firing rate. Grating conditions were presented in a randomized fashion, and each condition was presented at least 7 times.

Sparse noise. We used a sparse noise stimulus, consisting of static black or white squares presented one at a time on a gray background along a grid of $8 \times 16$ squares (each square $\sim 8 \mathrm{deg} \times 8 \mathrm{deg}$, for 3 of the initial experiments in awake animals) or $18 \times 32$ (each square $\sim 4 \mathrm{deg} \times 4 \mathrm{deg}$, for all other experiments) to map RFs. The squares were presented for either 200 or $250 \mathrm{~ms}$ for the awake mice and $200 \mathrm{~ms}$ for the anesthetized mice with 25-35 repeats. The position and luminance of the square on each presentation were chosen randomly while ensuring that each stimulus condition was sampled equally. Although this is a rather slow method to map RFs, we used it because it excites the ON and OFF subfields of the RF separately, thereby allowing us to map the ON/OFF responses at individual pixels, which was seen in many RFs. In the analysis of spatial RFs, we disregarded the RF recorded with 8 deg squares (70 $\mathrm{RF}$ in V1 awake [aw] and $65 \mathrm{RF}$ in dLGN aw) but included them for studying the temporal component of the response to flashed squares.

\section{Data analysis}

Data analysis was based on customized routines written in MATLAB (The MathWorks). For each stimulus set, we collected all spikes occurring between the beginning and end of a given stimulus condition and ascribed that set of spikes to the condition, after correcting for the $16 \mathrm{~ms}$ lag between the computer generating visual stimuli and display on the monitor. These were then used to calculate the firing rates as described below. Statistical significance was determined by nonparametric tests, such as Mann-Whitney $U$ test, Kruskal-Wallis tests, or otherwise stated. A Dunn's test was used with the Kruskal-Wallis test to correct for multiple comparisons. In box plots, error bars indicate 5th-95th percentiles, the crosses represent the means and finally the horizontal bars show the medians.

\section{Response to gratings}

Drifting sine-wave gratings were used to test neuronal responses to different directions, orientations, and spatial and temporal frequencies. We used the cycle-averaged firing histograms to compute the mean rate (F0) and fundamental (F1, at the input frequency) responses for each drifting grating condition ( $3 \mathrm{~s}$ each). Linearly summating cells are highly modulated by the drifting sinusoidal stimulus; for instance, a pure ON cell would be maximally excited by the light phase. Therefore, the modulated component (F1) is typically greater than the mean rate (F0). On the other hand, nonlinear cells (with low F1/F0 ratios) fire rather constantly throughout the stimulation by gratings and their responses are best characterized by F0 (Movshon et al., 1978b). Because the responses of most linearly summating cells are rectified at zero, the F0 and F1 responses typically track each other (a half-wave rectified sinusoid has an F1/F0 ratio of 1.57) (Movshon et al., 1978a). To compare all cells on an even footing, we calculated tuning curves using the mean evoked response (F0). Because we computed the F1/F0 index at the peak F0 and we did not subtract the baseline (Chen et al., 2009), our distributions are slightly biased toward lower values than in some studies.
For each orientation, we calculated an average response across all spatial and temporal frequencies tested. The orientation that evoked the greatest averaged response was taken to be the preferred orientation in subsequent calculations. The spatial and temporal frequencies that elicited the maximum response at the preferred orientation were then chosen to be the preferred frequencies, respectively. Orientation and direction selectivity indices (DSIs) were calculated directly from the tuning curve obtained from the F0 responses at the preferred spatial and temporal frequency.

To characterize orientation selectivity, we calculated an orientation selectivity index (OSI) that provides a global measure of tuning that incorporates both tuning width and depth of modulation (Swindale, 1998; Ringach et al., 2002; Niell and Stryker, 2010; Piscopo et al., 2013) as follows:

$$
\text { OSI }=\left|\frac{\sum_{k} r_{k} e^{2 i \theta_{k}}}{\sum_{k} r_{k}}\right|
$$

where $r_{k}$ is the F0 response at the preferred spatial and temporal frequency for each direction $\left(\theta_{k}\right)$. The OSI averages together both directions for each orientation and that it is equal to 1 - circular variance (Ringach et al., 2002).

The DSI was defined using the following:

$$
\text { DSI }=\frac{R_{\text {pref }}-R_{\text {null }}}{R_{\text {pref }}+R_{\text {null }}}
$$

where $R_{\text {pref }}$ is the response at $\theta_{\text {pref }}$ and $R_{\text {null }}$ is the response at $\theta_{\text {pref }}+\pi$

\section{Contrast response curves}

The contrast response was characterized using the response to the orientation closest to $\theta_{\text {pref. }}$ If the peak contrast response was at either extreme (either low-pass, i.e., suppressed by contrast, or high-pass), the response was fit with a sigmoidal function as follows:

$$
y=c+\frac{a}{1+e^{-k\left(x-x_{0}\right)}}
$$

where $x_{o}$ is the $\mathrm{C}_{50}$ (contrast at half-maximum response).

If the peak response was not at either extreme (i.e., bandpass), the response was fit with a Gaussian function as follows:

$$
y=c+a e^{\frac{-\left(x-x_{0}\right)^{2}}{2 \sigma^{2}}}
$$

where $x_{o}$ is the $\mathrm{C}_{\max }$ (contrast at maximum response)

\section{Sparse noise}

RFs for each cell were obtained from the sparse noise stimulus by calculating a trial-averaged firing rate evoked at every pixel in the $(8 \times 16)$ or $(18 \times 32)$ stimulus grid, for both black (OFF subfields) and white $(\mathrm{ON}$ subfields) squares. Spikes were binned into 10 equal bins spanning the stimulus duration. For each subfield, the bins and pixels at which the peak responses were elicited were first found. The larger of the ON and OFF peak responses was taken to be the maximum firing rate of the cell. Next, the trial-averaged mean firing rates within the peak bins were then used to estimate the sizes of the ON and OFF subfields. We interpolated each subfield using a 2D bilinear interpolation. All pixels in the interpolated grids that were $<35 \%$ of the cell's maximum firing rate were set to zero and a contiguous non-zero set of pixels, including peak pixel, were isolated (Zhuang et al., 2014). This set of pixels was taken to represent the respective subfields. The number of contiguous pixels was used to calculate the area of the ON and OFF subfields and their degree of overlap. Specifically, the subfield area and radius were calculated using the following:

Area $=$ number of contiguous non-zero interpolated pixels

$\times$ area of each pixel 


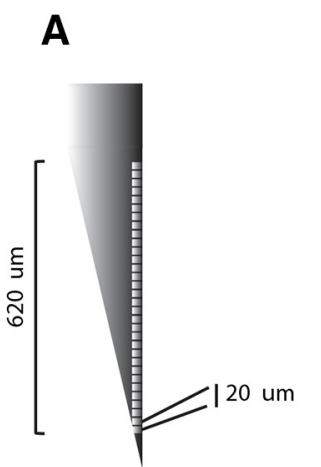

C
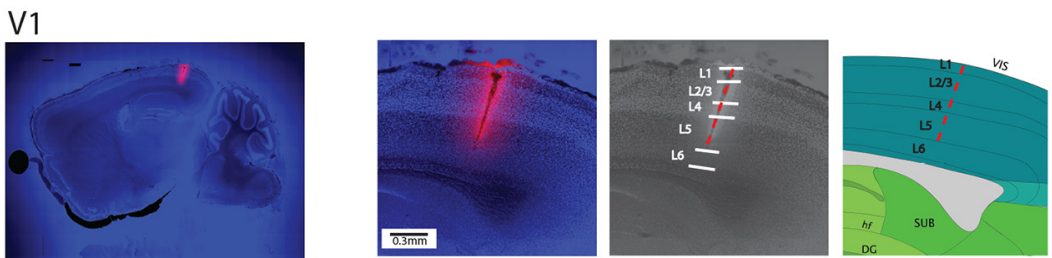

D

B
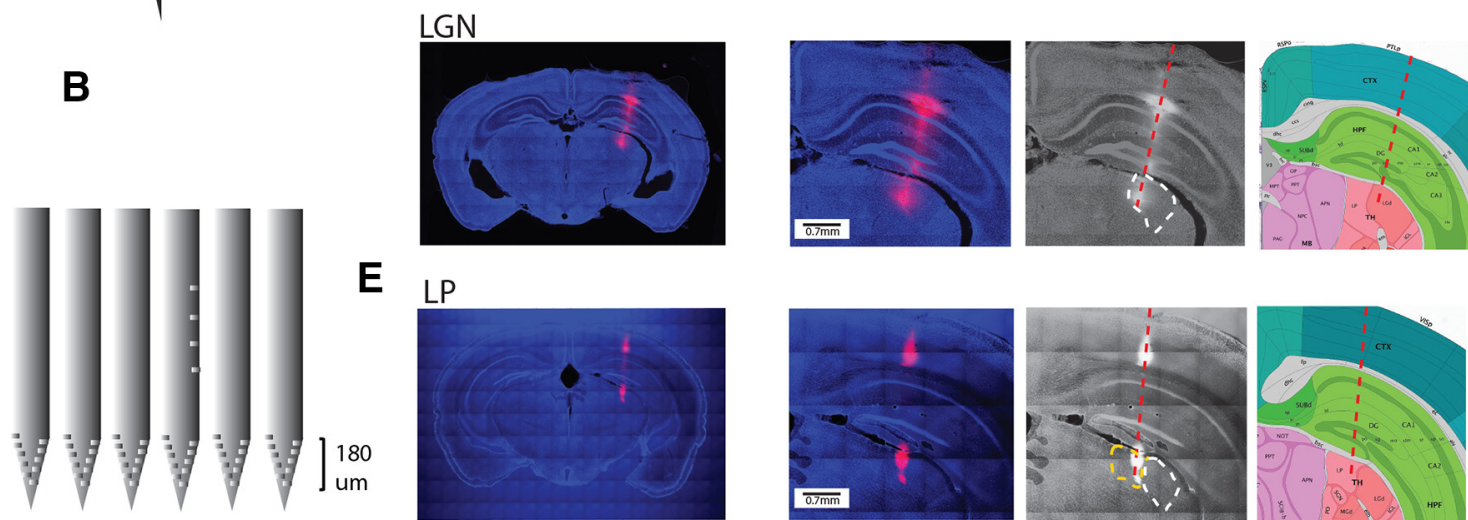

E
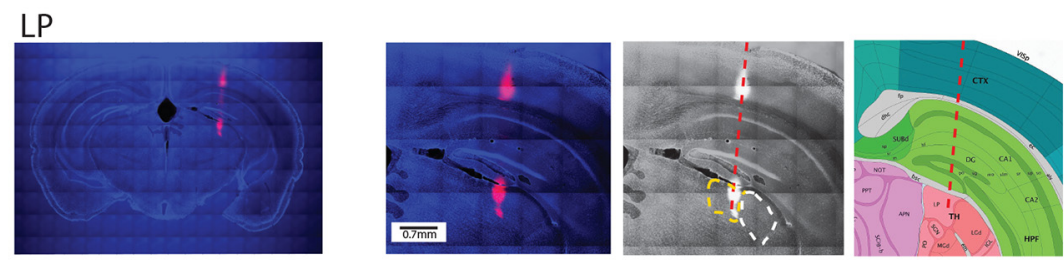

200 um

Figure 1. Localization of recordings. $A$, Schematic of a Neuronexus Edge 32 probe (32 channels on one side of a single shank) allowing an easy insertion in V1 through the dura. Recording sites sample $640 \mu \mathrm{m}$ in depth. B, Schematic of a Neuronexus Buzsáki64 (6 shanks) facilitating collection of data in the anteroposterior axis of dLGN. The recording channels span $180 \mu \mathrm{m}$. C, Example of a penetration in V1 on a sagittal section, Dye l is used to locate the electrode's track and is salient against backgrounds of DAPI staining. Using simultaneously the tissue slides (left) and the landmarks of the Allen Institute Atlas (Allen Institute for Brain Science, last panels on the right) allows to identify the lamination. $\boldsymbol{D}, \boldsymbol{E}$, Coronal sections of 2 mice, one with a penetration in dLGN (dLGN contours in dashed white) and another one in LP (LP contours in dashed yellow).

$$
\text { Radius }=\sqrt{ }(\text { Area } / \pi)
$$

The Overlap Area was calculated by finding the number of interpolated pixels common to both subfields and multiplying it by the area of each pixel and Union Area was calculated similarly using the union of the set of pixels from both subfields. The Overlap Index (OI) was calculated using the following:

$$
\mathrm{OI}=\frac{\text { Overlap Area }}{\text { Union Area }}
$$

The time courses of the responses were analyzed by creating a peristimulus time histogram (PSTH) at the peak pixels using a $20 \mathrm{~ms}$ Gaussian window. We found that, for almost all units, the faster responding subfield also had a higher peak firing rate, and we took this faster subfield to be the dominant one. The time to peak was taken to be the time at which each subfield attained its respective maximum firing rate. For each subfield, a Sustained Index was calculated by taking the ratio of the mean to the maximum firing rate as in Piscopo et al. (2013).

\section{Selection of cells}

For the analysis of orientation, spatial and temporal frequency tuning, we selected cells whose evoked response to the preferred grating stimulus was significantly different from the spontaneous rate ( $t$ test, $p<0.05)$. For the analysis of contrast response functions, only cells previously selected for orientation, spatial and temporal frequency tuning were used. For sparse noise analysis, we included units that showed significant responses for at least one subfield after RF estimation as described above. Because of the length of the initial protocol (orientation, spatial and temporal frequency), some spikes were lost for the subsequent contrast and RF characterizations (for cell counts, see Results).
RRIDs

Mouse C57BL6J. Electrophysiological recordings were performed in the left hemisphere of adult $\mathrm{C} 57 \mathrm{Bl} / 6$ mice (2-6 months, males); RRID: IMSR_JAX:000664.

Psychopy. Stimuli were generated in Python, using the Psychopy toolbox (Peirce, 2007) and were shown on an Asus PB238 screen $(1920 \times$ 1080 pixels, $51 \mathrm{~cm}$ wide, $60 \mathrm{~Hz}$ refresh rate) adjusted with a flexible arm to be $45^{\circ}$ from the anteroposterior axis, $11 \mathrm{~cm}$ from the mouse's eye, thus subtending $133^{\circ}$ of visual field; RRID: SCR_006571.

MATLAB. Data analysis was based on customized routines written in MATLAB (The MathWorks); RRID: SCR_001622.

KlustaKwick. Based on principal component analysis, the individual spikes were automatically clustered into groups using the KlustaKwik program (Harris et al., 2000), followed by manual adjustment of the clusters using the Klusters software package (http://klusters.sourceforge. net) (Hazan et al., 2006); RRID: SCR_014480.

Allen Reference Atlas. For 20 of 25 thalamic recordings, the Allen Mouse Brain Atlas (Lein et al., 2007) was used to confirm whether recordings were from dLGN or LP; RRID: SCR_013286.

\section{Results}

We used multisite silicon probes to study the physiological properties of neurons in the dLGN, LP, and V1 of both urethaneanesthetized (an) and awake mice (aw). Awake mice were generally stationary with short and rare running episodes, which were not analyzed separately. Most of recordings in dLGN were made using multishank silicon probes, whereas a single shank was generally used in V1 (Fig. 1). This single shank probe covers $620 \mu \mathrm{m}$ of cortical depth, allowing recording in layers $2 / 3$ through 6 , although we tended to undersample layer 6. Micro- 
electrodes were coated with a lipophilic dye (DiI) used to identify the laminar location of each recording site in the cortex and to determine whether the electrode shanks were in dLGN or LP (Fig. 1). In addition to looking at three brain areas, multiple cortical layers, and two brain states, we also isolated putative excitatory and inhibitory neurons based on their spike widths (Niell and Stryker, 2008). In total, we recorded from 1723 cells. Of these, we found cells that had statistically significant responses to gratings (see Materials and Methods): 232 in cortex, 456 in dLGN, and 35 in LP in the awake animal and 80,164 , and 5 , respectively, in the anesthetized animal.

\section{Putative excitatory and inhibitory neurons}

The width of action potentials has long been used to distinguish between putative excitatory and inhibitory neurons in the hippocampus and cortex (Mountcastle et al., 1969; Niell and Stryker, 2008; Sirota et al., 2008; Stark et al., 2013), as well as in the dLGN (Denman and Contreras, 2015), based on previous observations (Pape and McCormick, 1995; Williams et al., 1996). Units were classified as putative excitatory or putative inhibitory based on the width of the wide-band-filtered $(0.3 \mathrm{~Hz}$ to $10 \mathrm{kHz})$ spike waveform (Fig. $2 A$ ). In the anesthetized (data not shown) and awake cortex and dLGN, spike width had clearly multimodal distributions (Fig. 2B; Hartigan dip test, $p<0.001$ for both, cortex spike duration peaks at $0.18,0.41$, and $0.66 \mathrm{~ms}$, and at 0.14 and $0.32 \mathrm{~ms}$ in dLGN). We classified a cortical cell as putative inhibitory if the spike duration was $<0.3 \mathrm{~ms}$ (McCormick et al., 1985) and $<0.23 \mathrm{~ms}$ for dLGN cell. In the cortex, putative inhibitory cells represent $22 \%$ of neurons in the awake animal (nexc $=176$, ninh $=51$ ) and $15 \%$ $($ nexc $=66$, ninh $=12)$ in the anesthetized animal; $7 \%$ of dLGN neurons in the awake animal (nexc $=416$, ninh $=31$ ) and $8 \%$ $($ nexc $=150, \operatorname{ninh}=13)$ in the anesthetized animal were classified as putative inhibitory units. The mean duration of putative excitatory and inhibitory spikes was $0.48 \pm 0.0083$ and $0.18 \pm$ $0.0052 \mathrm{~ms}$ in $\mathrm{V} 1$ and $0.35 \pm 0.0038$ and $0.14 \pm 0.0045 \mathrm{~ms}$ in dLGN. Other measures of spike shape, such as the ratio of peak and trough times (Niell and Stryker, 2008), were less useful for differentiation between cells. When we applied this method to LP cells, with the same criteria as in dLGN, only one cell fell into the putative inhibitory class. As a result, we did not make the distinction in further analysis of LP responses.

\section{Spontaneous and evoked firing in response to drifting gratings}

Spontaneous rate, as well as the maximum firing rate, has been shown to be dependent on state (Niell and Stryker, 2010). We therefore assessed the spontaneous and maximum evoked firing rates in V1, dLGN, and LP in both awake and anesthetized mice. Spontaneous rate was defined as single-unit activity during presentation of a mean-luminance gray stimulus (Fig. $3 A$ ), whereas the maximum evoked firing rate represents the response to its preferred combination of grating parameters (orientation, spatial and temporal frequencies). Surprisingly, in V1, spontaneous firing rate was similar in awake and anesthetized states $(1.88 \pm 0.25$
B

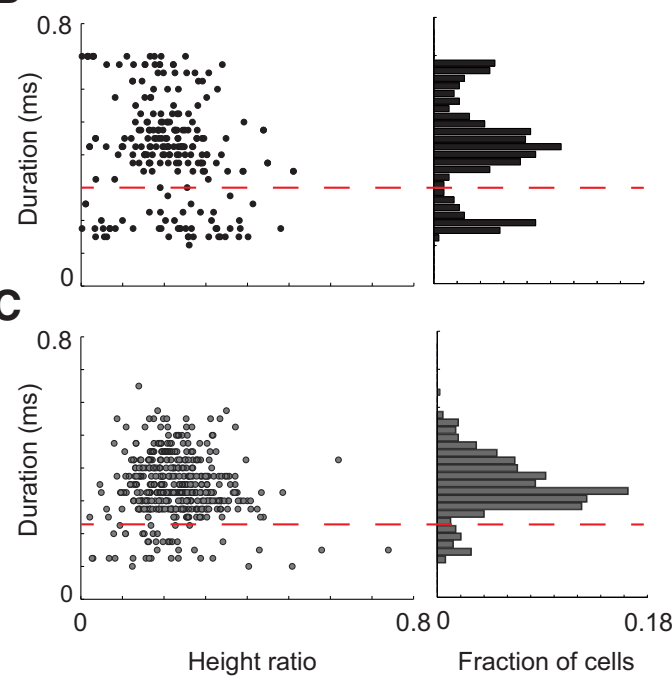

$1.79 \pm 0.29 \mathrm{sp} / \mathrm{s}$, not significant). However, the spontaneous firing rate was lower during anesthesia state in the dLGN (4.43 \pm 0.25 vs $2.65 \pm 0.27 \mathrm{sp} / \mathrm{s}$; Mann-Whitney test, $p=0.0003)$. Although LP spontaneous firing showed the same trend, the difference was not significant (aw: $3.91 \pm 0.44$; an: $2.582 \pm 0.68 \mathrm{sp} / \mathrm{s}$ ). Likewise, the maximum evoked firing rate was also low in geniculate cells of anesthetized mice $(8.83 \pm 0.52 \mathrm{vs} 11 \pm 0.41 \mathrm{sp} / \mathrm{s}$, Mann-Whitney test, $p=0.03)$, but not in V1 (6.98 \pm 0.54 vs $7.16 \pm 0.75 \mathrm{sp} / \mathrm{s}$ ), in contrast to previous reports (Niell and Stryker, 2010). V1 responsiveness has been shown to be greatly increased by running (Niell and Stryker, 2010), dLGN firing rates as well, but to a lesser extent (Erisken et al., 2014). The lack of effect of anesthesia on V1 spontaneous and maximum firing rate could be the consequence of averaging firing rates over a mixture of physical activities and would be less true in the dLGN.

In both awake (aw) and anesthetized (an) states, the spontaneous firing rate was lower in L2/3 compared with L4 and 5 (aw: $0.58 \pm 0.11,3.00 \pm 1.14$, and $2.86 \pm 0.65 \mathrm{sp} / \mathrm{s}$, Mann-Whitney test, $\mathrm{L} 2 / 3$ vs L4, $p=0.0043$ and L2/3 vs L5, $p<0.0001$; an: $0.38 \pm$ $0.22,1.58 \pm 0.37$, and $2.63 \pm 0.76 \mathrm{sp} / \mathrm{s}$, Mann-Whitney test, L2/3 vs L4, $p=0.0026$ and L2/3 vs L5, $p=0.0001$; Fig. $3 A$ ). For the maximum evoked rate, no significant difference was found between layers (Kruskal-Wallis test, not significant).

\section{Spatial summation}

The linearity of spatial summation has long been used to classify neurons in the retina (Enroth-Cugell and Robson, 1966), dLGN (Shapley and Hochstein, 1975), and visual cortex (Movshon et al., 1978a, b; Skottun et al., 1991; Chen et al., 2009). For linearly summating neurons, responses to drifting sinusoidal stimuli are modulated at the grating's drift frequency (F1), whereas nonlinear neurons typically respond with an increased mean rate (F0) without temporal modulation. We found a bimodal distribution of F1/F0 for excitatory neurons in V1 (Niell and Stryker, 2008; Gao et al., 2010) with a trough near 1.0 (the boundary we used between linear and nonlinear), which did not vary with state (Fig. 3B; aw: median $=0.87$; an: 0.90) (Zhuang et al., 2014). Although there 


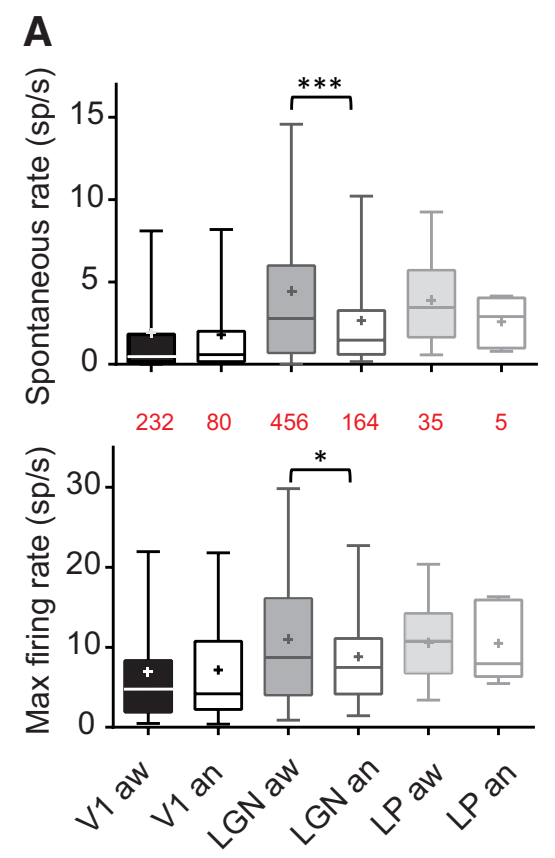

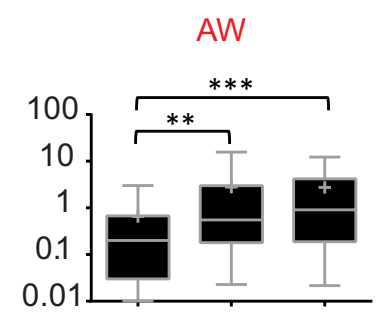

35

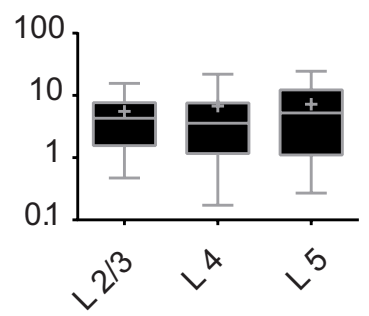

AN

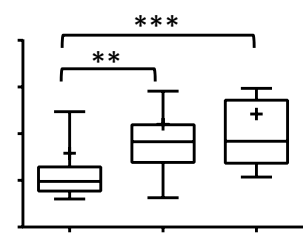

$\begin{array}{lll}15 & 39 & 10\end{array}$

B

V1

LGN
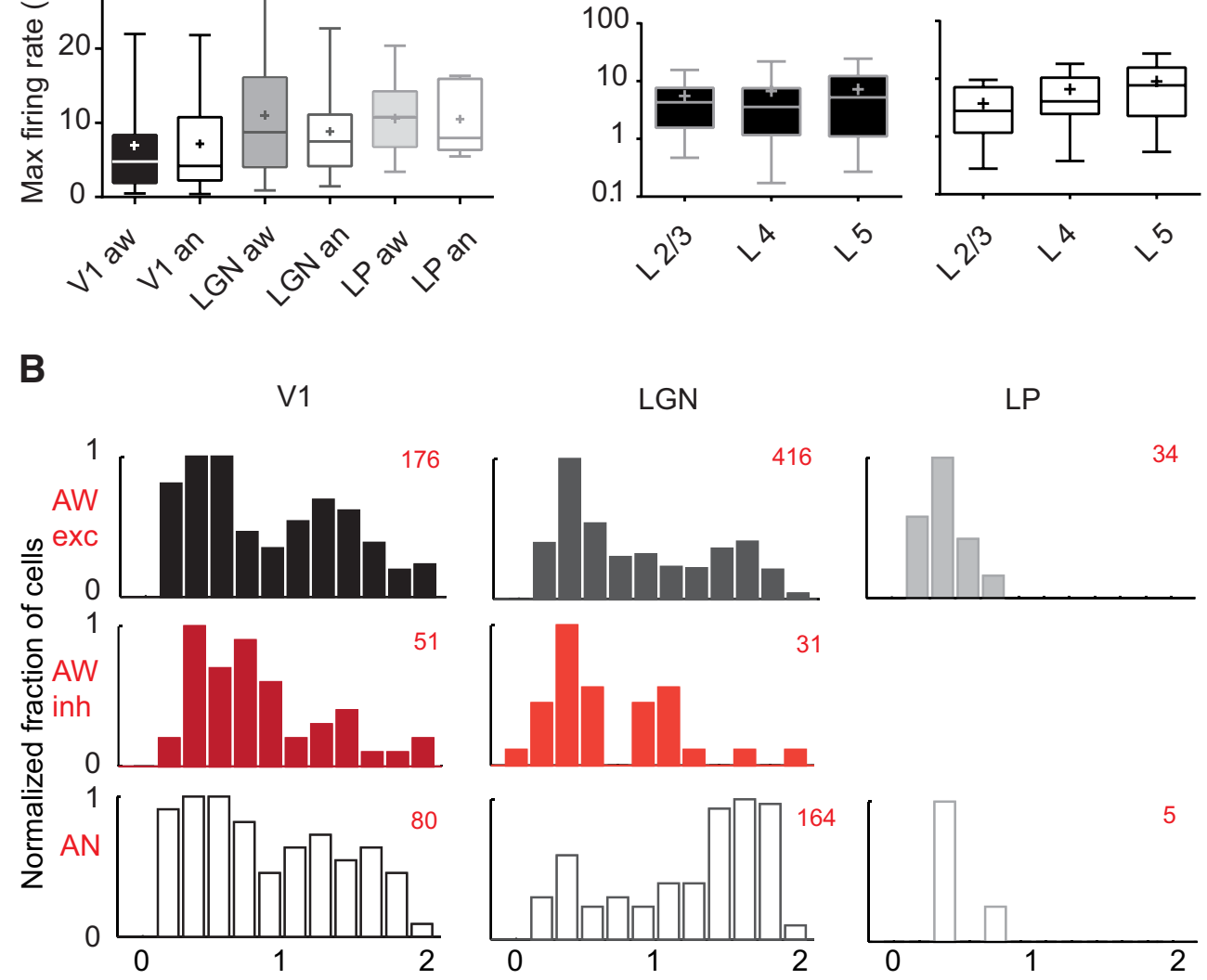

F1/F0

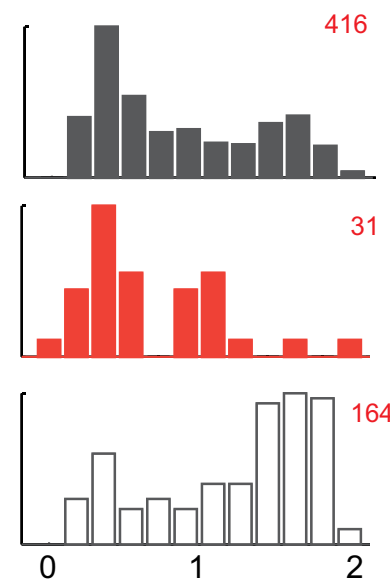

F1/F0

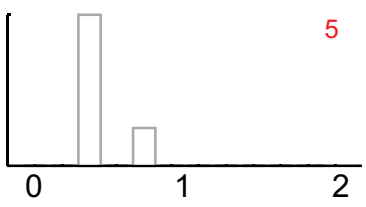

F1/F0

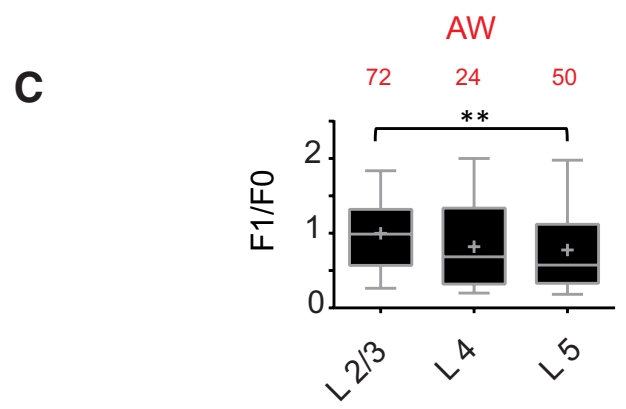

AN

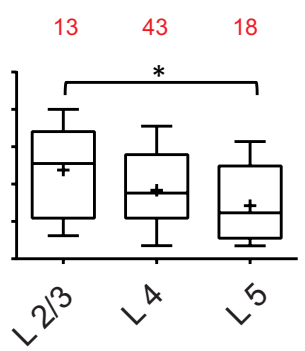

Figure 3. State effect on firing rates and linearity in V1, dLGN, and LP. A, First column, Mean spontaneous and maximum evoked firing rates for the 3 areas and 2 states. Red represents the number of cells recorded for each condition. Box plots represent medians as a bar, mean as a cross, and illustrate 5th and 95th percentiles. Under anesthesia, spontaneous rate decreases only in dLGN (Mann-Whitney test, $p=0.0003$ ). Maximum evoked firing rate is not showing statistical dependence on state in V1 and LP, but it is in dLGN (Mann-Whitney test, $p=0.03$ ). Second and third columns, Firing rates by layer. Low spontaneous firing rate is seen in $L 2 / 3$ in both states: Mann-Whitney test, $L 2 / 3$ vs $L 4, p=0.0043$ (aw) and 0.0026 (an); $L 2 / 3$ vs $L 5, p<0.0001$ (aw and an). Maximum firing rate levels do not vary with cortical layer and state: $\mathrm{L} 2 / 3 \mathrm{vs} L 5$ : Kruskal-Wallis test, not significant (aw and an). $\boldsymbol{B}, \mathrm{F} 1 / \mathrm{F} 0$ index distributions in 3 areas. The number of units recorded are in red. Awareness does not alter spatial summation in V1 and LP. In dLGN, there is a significant shift toward more complex responses from anesthesia to awake state (solid gray; Mann-Whitney test, $p<0.0001$ ). Few putative inhibitory cells (red) have a high value of F1/F0 ratio in V1 and dLGN. LP cells (light gray) are exclusively nonlinear. C, Distribution of F1/F0 index per cortical layers for all cells. In both states, $L 5$ is the layer with the smallest mean of F1/F0 (Mann-Whitney test, aw: L2/3 vs L5: $p=0.0092 ;$ an: 0.0175$) .{ }^{*}, p<0.05 ;{ }^{* *}, p<0.01 ;{ }^{* * *}, p<0.001$. 
were significant differences between the distributions of F1/F0 between the cortical layers, anesthesia did not significantly affect these distributions either globally or for individual layers. For example, layer 5 in both awake and anesthetized states contained units with low F1/F0 (Fig. 3C). In the dLGN, however, the F1/F0 was skewed toward higher values (more linear) under anesthesia, compared with the awake state (Fig. 3B; aw: median $=0.64$, an: 1.42 , MannWhitney test, $p<0.0001)$. This change might be explained by the observed increase in spontaneous rate in dLGN of awake mice (Fig. 3A). This elevation of activity is likely to affect geniculate neurons linearity by elevating the F0 component. We also examined the linearity of putative excitatory versus inhibitory cells. As previously shown, a larger proportion of cortical and geniculate putative inhibitory cells recorded are nonlinear than excitatory cells (Fig. 3B) (Niell and Stryker, 2008; Liu et al., 2009; Ma et al., 2010; Zhuang et al., 2014). Nonlinear units represent $56 \%$ of excitatory $\mathrm{V} 1$ cells and $70 \%$ of putative inhibitory cells. Likewise, in the dLGN, $65 \%$ of excitatory cells and $81 \%$ of inhibitory cells are nonlinear. The most striking feature distinguishing LP cells recorded from cells in other areas is that they are exclusively nonlinear (median aw 0.34 ; median an: 0.38 ).

\section{Selectivity to orientation and direction}

The orientation selectivity of neurons in the dLGN, LP, and V1 was measured in response to drifting gratings (see Material and Methods; Fig. 4A) and quantified by measuring the OSI, defined as a global measure of the shape of the tuning curve (see Materials and Methods; Fig. 4A). Whereas the neurons in V1 had a mean OSI of $0.42 \pm 0.02$ in the awake state, dLGN and LP neurons are equally poorly tuned with a mean of $0.22 \pm 0.01$ and $0.23 \pm 0.02$ (Fig. $4 B$ ), consistent with previous studies (Piscopo et al., 2013; Kondo and Ohki, 2016; Roth et al., 2016). Surprisingly, the OSIs of V1 neurons were lower during anesthesia, due primarily to a strong and significant effect in L4 (L4 aw $0.48 \pm 0.05$ vs L4 an $0.31 \pm 0.02$, MannWhitney test, $p=0.007$, not significant for L2/3 and L5; Fig. 4C, red stars). The same tendency has been observed in simple cells of layer 4 in rabbit, between alert and nonalert states (Zhuang et al., 2014). We found no significant state-dependent differences in OSI for dLGN and LP. Consistent with previous reports (Niell and

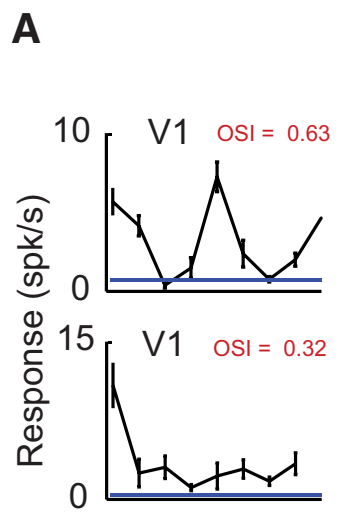

B
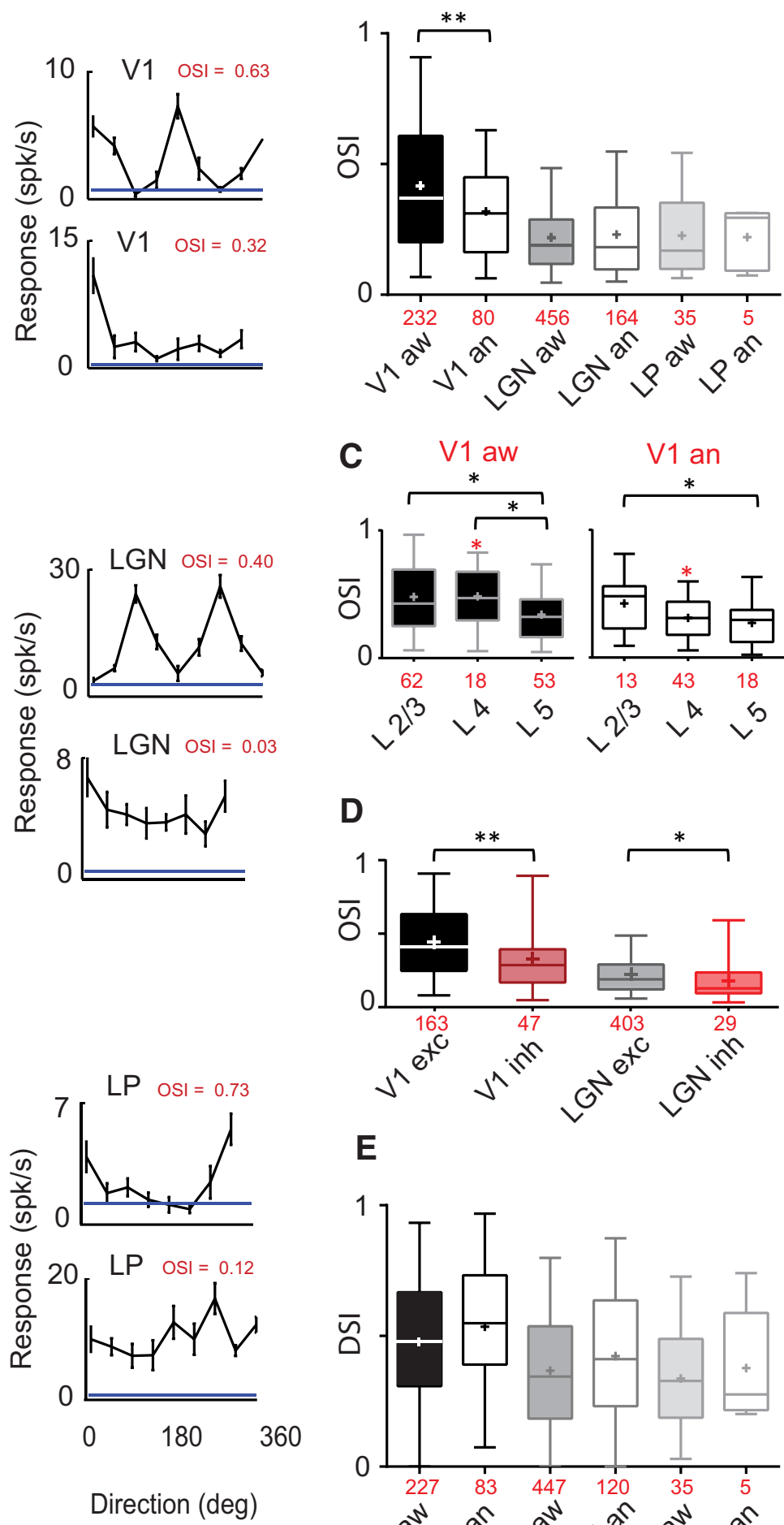

E

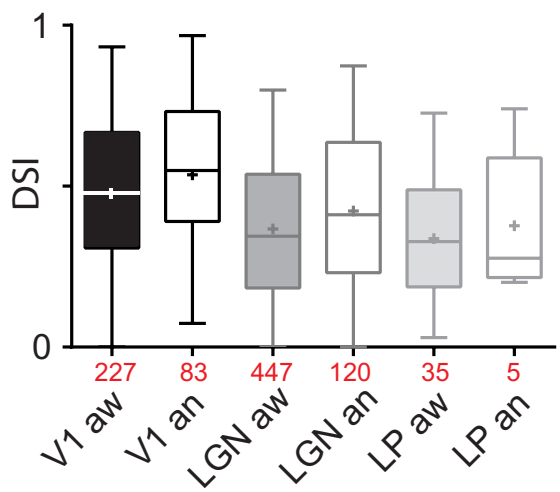

Figure 4. Orientation and direction selectivity. $A$, Tuning curve examples from $\mathrm{V} 1, \mathrm{dLGN}$, and $\mathrm{LP}$, with high and low $0 \mathrm{SI}$ (red). Blue lines indicate the mean spontaneous rate for each example cell in spikes/s. B, Mean OSI for 3 areas and 2 states. Cell count is in red. Box plots represent medians as a bar, mean as a cross, and illustrate 5 th and 95 th percentiles. A decrease in $0 S$ I is exclusively observed in anesthetized V1 (Mann-Whitney test, $p=0.0056$ ). C, Laminar selectivity for orientation. L 5 is the layer with the least orientation tuning, especially compared with layer $2 / 3$ (Mann-Whitney test, aw: $p=0.0127$; an: 0.0379 ). An increase in L 4 cell selectivity is observed in awake mice (Red stars, Mann-Whitney test, $p=0.0072$ ). $\boldsymbol{D}$, Mean CV for excitatory and inhibitory neurons in $\mathrm{V} 1$ and dLGN. Putative inhibitory cells are less tuned for orientation than putative excitatory cells, in both areas (V1, Mann-Whitney test, $p=0.0029 ; \mathrm{dLGN}, p=0.0375$ ). $\boldsymbol{E}$, DSI does not significantly change with states (Kruskal-Wallis, not significant). Putative excitatory and inhibitory cells are grouped together when not explicitly separated into two groups. ${ }^{*}, p<$ $0.05 ;{ }^{* *}, p<0.01 ;{ }^{* * *}, p<0.001$. 
A

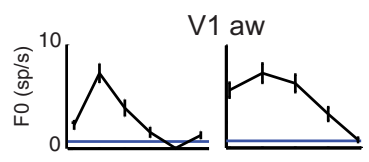

V1 an

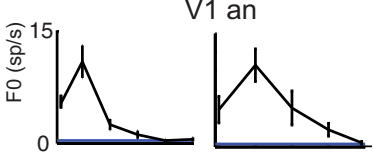

LGN aw
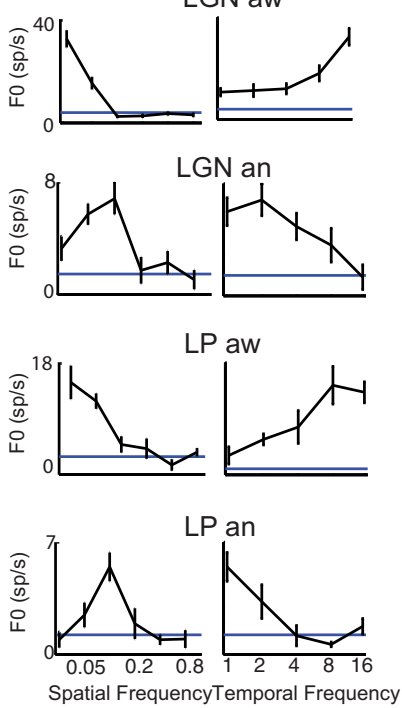

(cpd)

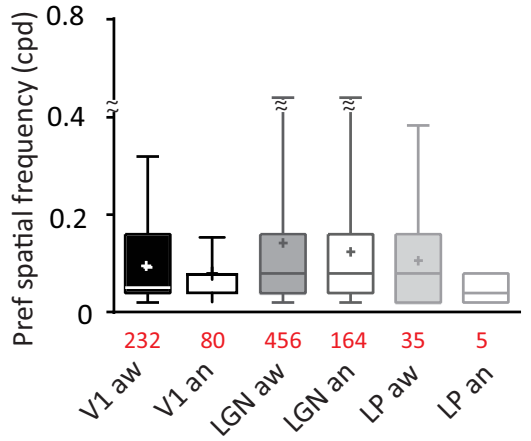

C

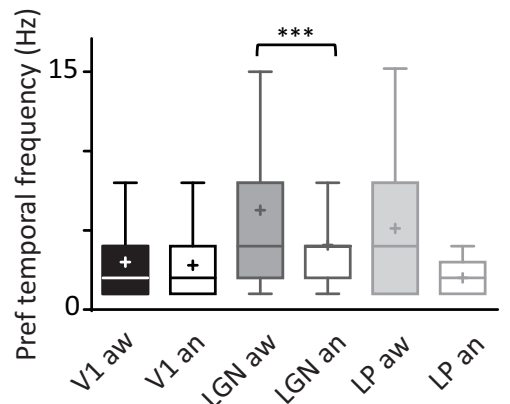

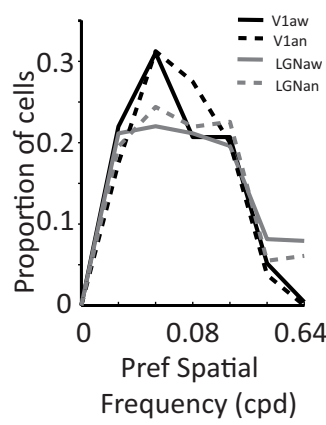

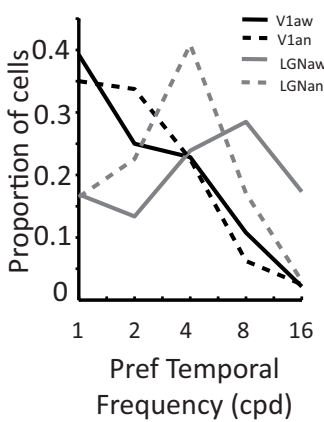

Figure 5. Spatial and temporal preferences. $\boldsymbol{A}$, Representative examples of spatial and temporal frequency (SF and TF) tunings for the same cells seen in Figure $4 A$. $\boldsymbol{B}$, Left, Box plots represent medians as a bar, mean as a cross, and illustrate 5 th and 95 th percentiles. Mean peak SF across layers is not significantly affected by state (Kruskal-Wallis test, not significant), (right) proportion of cells responding optimally to SF tested. C, Left, Mean peak TF is decreased in anesthetized dLGN (mean. $6.27 \pm 0.22 \mathrm{vs} 4.07 \pm 0.23 \mathrm{~Hz}$; Mann-Whitney test, $p<0.0001$ ). Right, proportion of cells responding optimally to TF tested. ${ }^{*}, p<0.05 ;^{* *}, p<0.01 ;{ }^{* * *}, p<0.001$.

Stryker, 2008; Liu et al., 2009; Kerlin et al., 2010; Ma et al., 2010; Hofer et al., 2011), we observed that cortical and geniculate putative inhibitory cells show significantly lower OSI values than putative excitatory cells (V1: $0.33 \pm 0.03$ vs $0.44 \pm 0.02$; Fig. $4 D$; dLGN: $0.18 \pm 0.03$ vs $0.22 \pm 0.007)$. Noticeably, both populations of putative excitatory and inhibitory neurons contain highly tuned as well as untuned cells; nonetheless only $21 \%$ of putative inhibitory cells in the awake animal had a OSI $\geq 0.5$, which falls in the range of selectivity observed in previous studies (Sohya et al., 2007; Hofer et al., 2011; Niell and Stryker, 2008; Runyan and Sur, 2013; Kerlin et al., 2010).

Consistent with the literature (Mangini and Pearlman, 1980; Niell and Stryker, 2008), we found broadly tuned cells, particularly in L5 (Fig. 4C). Unlike in layer 4, however, the orientation selectivity of layer 5 neurons was not modulated by state. In the awake mouse, we observed that $38 \%$ of nonlinear excitatory units $(\mathrm{F} 1 \mathrm{~F} 0$ index $<1)$ are selective for orientation (OSI > 0.3) against $56 \%$ for linear cells, reflecting the low selectivity observed in nonlinear cells in other species.

We used a DSI (see Materials and Methods) that yields values near 0 if a cell responds nearly identically to both directions of motion at the peak orientation, or near 1 if one direction yields responses near zero for one direction. We found that $\mathrm{V} 1$ is more strongly direction selective than dLGN and LP $(0.48 \pm 0.02$ vs $0.37 \pm 0.01$ and $0.34 \pm 0.04$, Kruskal-Wallis test, dLGN vs V1: $p<0.0001$, LP vs V1: $p<0.01$; LP vs dLGN: not significant). No change in DSI was observed between states in V1, dLGN, and LP (Kruskal-Wallis test, not significant; Fig 4E).

\section{Spatial and temporal tuning}

To characterize the spatial frequency (SF) and temporal frequency (TF) tunings, we identified the SF/TF pair that evoked the strongest response at the optimal orientation (Fig. 5A). The means of the optimal SFs were not statistically different between awake and anesthetized mice (Mann-Whitney test, not significant; Fig. 5B, left). The median preferred SFs in the awake animal tended to be slightly higher in the thalamus (median dLGN, 0.08; LP, 0.08 cycles/deg, or cpd) than in V1 $(0.05 \mathrm{cpd})$, but not significantly different (Mann-Whitney test, not significant; Fig. $5 B$, left). The values for $\mathrm{V} 1$ are in agreement with a study using twophoton imaging (Andermann et al., 2011), but otherwise all values were higher than those previously found in electrophysiology experiments (Grubb and Thompson, 2003; Niell and Stryker, 2008; Gao et al., 2010; Piscopo et al., 2013). The optimal SF spanned a broad range, from 0.02 to $0.32 \mathrm{cpd}$ in V1 and to 0.64 cpd in dLGN. Fully $26 \%$ of cells in V1 and $36 \%$ in dLGN responded best to a SF of at least $0.16 \mathrm{cpd}$ (Fig. $5 \mathrm{~B}$, right). Most studies have presented gratings with low SF, generally between 0.01 and 0.32 cpd with 1 or 2 TF (Grubb and Thompson, 2003; Niell and Stryker, 2008; Piscopo et al., 2013). Here, we used a 
A

\section{B}
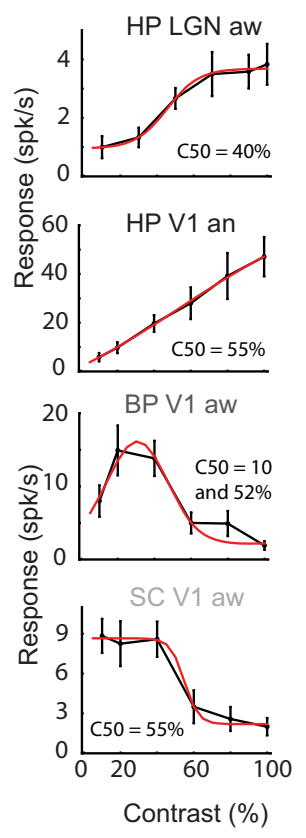
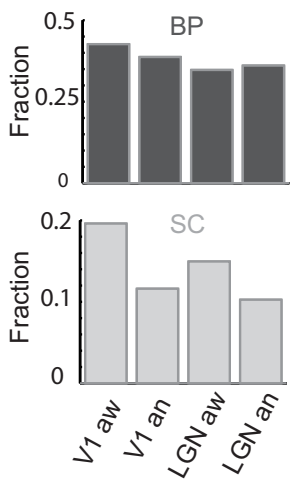

Figure 6. Three categories of contrast response curves. $A$, Representative examples of each category. Cells were classified HP when fitted with a sigmoid with or without plateau (2 top rows), bandpass (BP, third row) when fitted with a Gaussian or suppressed by contrast (SC, bottom row) when fitted with a negative sigmoid. $B$, Fraction of cells of each category in $\mathrm{V} 1$ and dLGN for both states. A higher percentage of SC cells are found in $\mathrm{V} 1$ aw vs $\mathrm{V} 1$ an (20\% vs $11 \%$ ).

combination of SF between 0.02 and $0.8 \mathrm{cpd}$ and 5 different TF between 1 and $16 \mathrm{~Hz}$. The low SF reported previously might have resulted from the use of nonoptimal combinations of SF and TF.

Neurons in the awake dLGN tended to have higher peak temporal frequencies than under anesthesia (Fig. $5 C$, left; mean: $6.27 \pm 0.22$ vs $4.07 \pm 0.23 \mathrm{~Hz}$; Mann-Whitney test, $p<0.0001$ ); $46 \%$ of dLGN cells in the awake state responded to TF equal to or $>8 \mathrm{~Hz}$, compared with only $20 \%$ of cells in the anesthetized state (Fig. $5 C$, right). This is similar to changes seen between alert and inattentive states in the rabbit dLGN (Bezdudnaya et al., 2006). For V1 neurons, no significant differences in the peak TF were detected (aw: $2.99 \pm 0.18$; an: $2.8 \pm 0.3 \mathrm{~Hz}$ ), which was expected from the literature (Zhuang et al., 2014). Overall, peak SF and TF were very similar between dLGN and LP (Mann-Whitney test, not significant).

\section{Contrast}

We observed a diversity of contrast responses (Fig. 6A) in both thalamus and V1. Monotonic or high-pass responses (HP) were well fit by a sigmoid curve that often saturated at high contrasts (Fig. 6A, first row), but not always (Fig. 6A, second row). Bandpass (BP) responses (Fig. 6A, third row) showed relative suppression at high contrast and were well fit by a Gaussian. Some cells were progressively suppressed below baseline by increasing contrast. These suppressed-by-contrast (SC) cells were best fit by a negative sigmoid. Most of these observations were well preserved across states. Surprisingly, the awake cortex contained twice the number of SC cells ( $20 \%$ vs $11 \%$; Fig. $6 \mathrm{~B}$, bottom row). A higher number of SC cells is also observed in dLGN ( $15 \%$ vs $10 \%$; Fig. $6 B$, bottom row). This is perhaps a result of the increased inhibitory tone that has been described in the awake animal (Haider et al., 2013).

\section{Spatial and temporal characteristics of RFs}

To determine RF structure and timing, we measured the responses to small black and white squares flashed at different positions on the screen. This sparse noise stimulus allowed us to delineate ON (light increment) and OFF (light decrement) subregions to quantify their relation in space and time. Spatial maps of the responses to the ON and OFF stimuli were derived from response averaging at each position in the grid (Fig. 7A). This method allows one to determine the polarity (ON, OFF, and $\mathrm{ON} / \mathrm{OFF}$ ) and sustainedness (sustained vs transient) of responses to flashed squares. We observed all types of RF with different combinations of characteristics, including transient ON cells in dLGN (data not shown) which were not observed in a previous study (Piscopo et al., 2013). We initially recorded from 1723 cells of which 195 dLGN, 42 LP neurons, and 177 cortical neurons in the awake animal and 112 and 44 in dLGN and V1 in the anesthetized state had an RF map.

We found that anesthesia did not affect the RF areas or radii of geniculate and cortical cells (area: Fig. $7 B$, top; $133.6 \pm 18.64$ vs $101.6 \pm 11.21$ and $146.1 \pm 12.78$ vs $122.3 \pm 15.49 \mathrm{deg}^{2}$, MannWhitney test, not significant; radii: Fig. $7 B$, middle, bottom panels; V1_ON: $5.36 \pm 0.36$ vs $5.11 \pm 0.38$ and V1 OFF: $5.40 \pm 0.23$ vs $4.92 \pm 0.49$; dLGN ON: $4.83 \pm 0.50$ vs $4.91 \pm 0.41$; dLGN OFF: $5.71 \pm 0.37$ vs $4.90 \pm 0.25 \mathrm{deg})$. Overall, these observations in V1 and dLGN are within the range of overlap and size previously reported in anesthetized mice (Liu et al., 2009; Smith and Häusser, 2010; Lien and Scanziani, 2013).

RFs in LP were larger than those of V1 and dLGN by a factor of $\sim 6$. Most LP cells (59\%) had overlapping ON and OFF responses, whereas OFF subunits were systematically bigger than ON subfields, as observed previously by Piché et al. (2015) (Fig. $7 B$, middle and bottom panels; OFF radii: $18.14 \pm 1.10$; ON radii: $8.32 \pm 1.22 \mathrm{deg})$. Because of LP RF size, they also present the largest separation between 2 subfields (Fig. 7C, top; $26.42 \pm 4.99$ vs $5.64 \pm 0.45$ in v1 and $5.41 \pm 0.87$ deg; Kruskal-Wallis test, $p<$ $0.0001)$.

To quantify the degree of overlap between ON and OFF subunits, we measured the Overlap Area and an Overlap Index (OI) (Hirsch et al., 1998). The average Overlap Area and OI were very similar for V1, dLGN, and LP (Kruskal-Wallis test, not significant). This result might seem surprising since previous studies in LP reported a somewhat larger proportion of cells with a high $(>0.5)$ OI (Piché et al., 2015). This is likely due to the thresholding method we used to isolate spatial RFs, which was perhaps not well suited for LP RFs due to their large size relative to the stimulus pixels, unlike for the dLGN and V1 RFs in this study, or the LP in previous work (Piché et al., 2015).

On examination of the kinetics of the response to flashed squares (at the pixel that evoked the strongest response), we observed two types of responses over time: transient responses reached a peak firing rate, and returned to near baseline within the duration of the stimulus (200-250 ms), whereas sustained responses maintained a high firing rate throughout the stimulus (Fig. 8A). This difference is reflected in the Sustained Index (SI, see Materials and Methods). In anesthetized mice, dLGN and LP responses were significantly less sustained than in the awake state (means awake vs anesthetized: dLGN, $0.38 \pm 0.008$ vs $0.34 \pm$ 0.007 ; LP, $0.38 \pm 0.01$ vs $0.30 \pm 0.03$; dLGN: Mann-Whitney test, $p=0.005$; LP: Mann-Whitney test, $p=0.037$; Fig. $8 B$, top), although the effect in the dLGN was fairly small $(11 \%)$. This observation is in accordance with studies that examined the influence of state on responses of dLGN in the cat (Sawai et al., 1988; Funke and Eysel, 1992). We did not observe a significant 
A
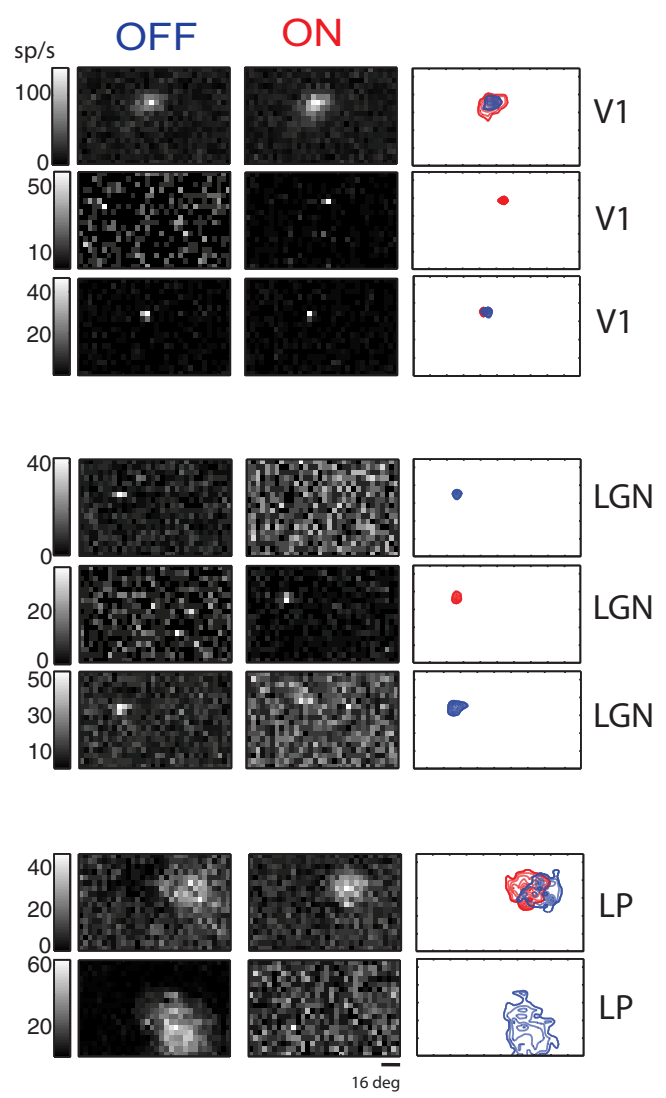

B
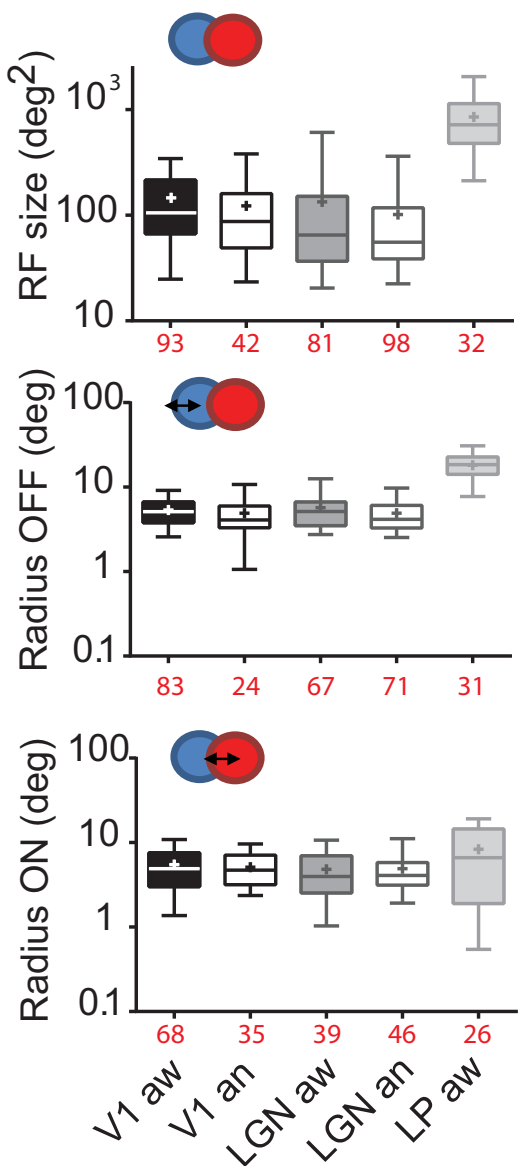

C
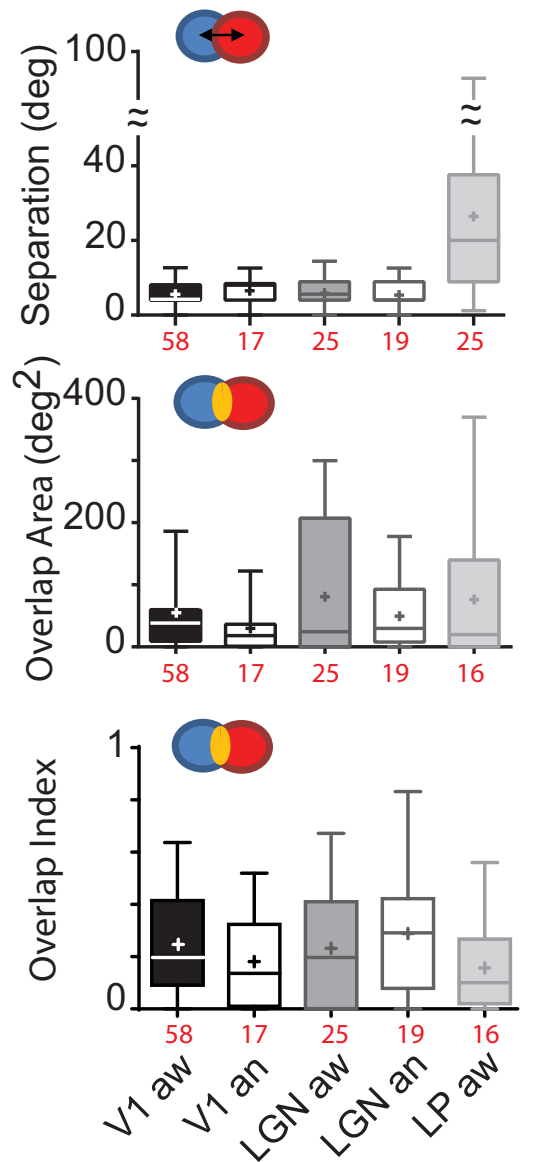

Figure 7. RF spatial characteristics. $\boldsymbol{A}$, Examples of $\mathrm{ON}$ and OFF subfields maps at their peak response and after linear interpolation. Next, contours and overlap are depicted: blue represents 0 FF; red represents 0 N. $B$, RF size and ON-OFF radii. Throughout, box plots represent the 5 th-95th percentile, bars represent medians, and crosses represent the means for each condition. RF size and radii are constant over states. LP RF size is on average 6 times bigger than those of dLGN. C, Subfield separation represents the distance between subfields centers. LP shows the biggest subfield separations between ON ad OFF subfields. OI (Overlap Index) is 1 if both ON and OFF overlap completely. The average Overlap Area and OI area are very similar for V1, dLGN, and LP (Kruskal-Wallis test, not significant).

change of time course in V1 (mean: V1, $0.35 \pm 0.007$ vs $0.34 \pm$ $0.35)$. Such a cortical state-based change has been observed in rabbits but restricted to layer 4 (Zhuang et al., 2014). Putative inhibitory cells had less sustained responses than excitatory cells (Fig. $8 C$, top; mean: $0.390 \pm 0.01$ vs $0.317 \pm 0.018$; Mann-Whitney test, $p=0.0009$ ).

Finally, we investigated the state dependence of the time to peak (TTP) response in PSTH (Fig. $8 B, C$, bottom panels). First, our results demonstrate a relative delay between successive processing stages, flashing stimuli elicit the shortest latency in dLGN followed by the responses of V1 cells, which has been seen in other species (Raiguel et al., 1989). Second, anesthesia delayed the TTP of the response in V1, dLGN, and LP and for both ON and OFF responses (means, V1: $96.88 \pm 2.11$ vs $120.30 \pm 2.94$; dLGN: $85.02 \pm 2.27$ vs $101.40 \pm 2.02$; LP: $98.17 \pm 3.75$ vs $126.3 \pm 7.36$ ms; Mann-Whitney test, $p<0.0001$ for V1 and dLGN; $p=$ 0.0003 in LP). As might be expected, the TTP of transient cells was shorter than those of sustained cells (sustained cells with SI > $0.3)$.

\section{Discussion}

We have measured the RF properties of dLGN, V1, and LP neurons in both awake and anesthetized mice. The use of the same visual stimuli and analyses allowed for direct comparisons between the three areas and the two states.

\section{Comparison with previous studies}

In awake mice, we recapitulated a number of distinctions between cell populations in the dLGN and V1 that have been described previously for anesthetized animals. Geniculate cells have higher firing rates (spontaneously and evoked) than cortical cells. Responses from putative excitatory neurons in V1 tend to have a higher degree of orientation and direction selectivity than dLGN or putative inhibitory V1 neurons (Niell and Stryker, 2008). V1 neurons tended to have peak responses at lower temporal frequencies than dLGN neurons (Grubb and Thompson, 2003; Niell and Stryker, 2008). Compared with other layers in V1, L5 cells show low orientation selectivity and are more nonlinear (Niell and Stryker, 2008). When mapped with sparse noise stimuli, RFs in dLGN are smaller than those in V1. Results from LP cells, which have been far less studied, allowed for new comparisons.

\section{Comparison of RF properties in dLGN and LP}

Overall, functional properties in response to drifting gratings were quite similar in dLGN and LP. We observed high spontane- 
ous rate, high maximum firing rate, low OSI (Roth et al., 2016), and comparable DSI, SF, and TF. LP neurons were similar to dLGN neurons in all of the above attributes except two: their RFs were considerably larger and they responded nonlinearly to drifting gratings.

State changes in LP mirror equivalent changes in the dLGN. Even though differences between states were not statistically significant for some properties, due to the low number of anesthetized LP cells, changes in LP followed the same trends as in dLGN. For example, spontaneous rate and temporal frequency were reduced with anesthesia. Additionally, a more robust result shows that anesthesia leads to less sustained responses with a slower time to peak. These observations indicate that urethane anesthesia similarly affects the dLGN and LP.

In the cat, LP is divided in LP lateral $(\mathrm{LPl})$, receiving predominant inputs from the cortex with RF size up to $700 \mathrm{deg}^{2}$ (Chalupa and Abramson, 1989) and LP medial (LPm) with mainly inputs from the superior colliculus (SC) with much bigger RFs, up to $2000 \mathrm{deg}^{2}$ (Chalupa et al., 1983). The range of RF sizes observed here were bigger than those found in another study (Roth et al., 2016) and fits more the characteristics of very large RFs reminiscent of those seen in cat LPm. LP in the mouse is also divided in different compartments, but their role and characteristics, to our knowledge, have not yet been revealed.

\section{Brain state-dependent characteristics}

We observed three differences in the temporal response properties in the awake compared with the anesthetized state. First, thalamic neurons respond maximally to higher temporal frequencies of drifting gratings in the awake state, reminiscent of the finding that rabbit dLGN cells respond to higher peak temporal frequencies in alert compared with inattentive states (Bezdudnaya et al., 2006). In V1, however, we did not find a statistically significant increase in preferred temporal frequency, consistent with results from calcium imaging in the awake animal (Andermann et al., 2011) compared with anesthetized (Niell and Stryker, 2008). Interestingly, the increase in preferred TF in dLGN does not translate in a corresponding shift in preferred TF for L4 cells, despite a broadening of the tuning curve (Zhuang et al., 2014). Second, there was a shorter latency to peak response to a $250 \mathrm{~ms}$ flashed stimulus in awake animals, both in the dLGN and V1 (Fig. $8 B$, lower panel). Both of these effects are consistent with a higher conductance in the awake state, particularly in the LGN because the cortical effect might be inherited, with an associated $0.01 ;{ }^{* * *}, p<0.001$.
B
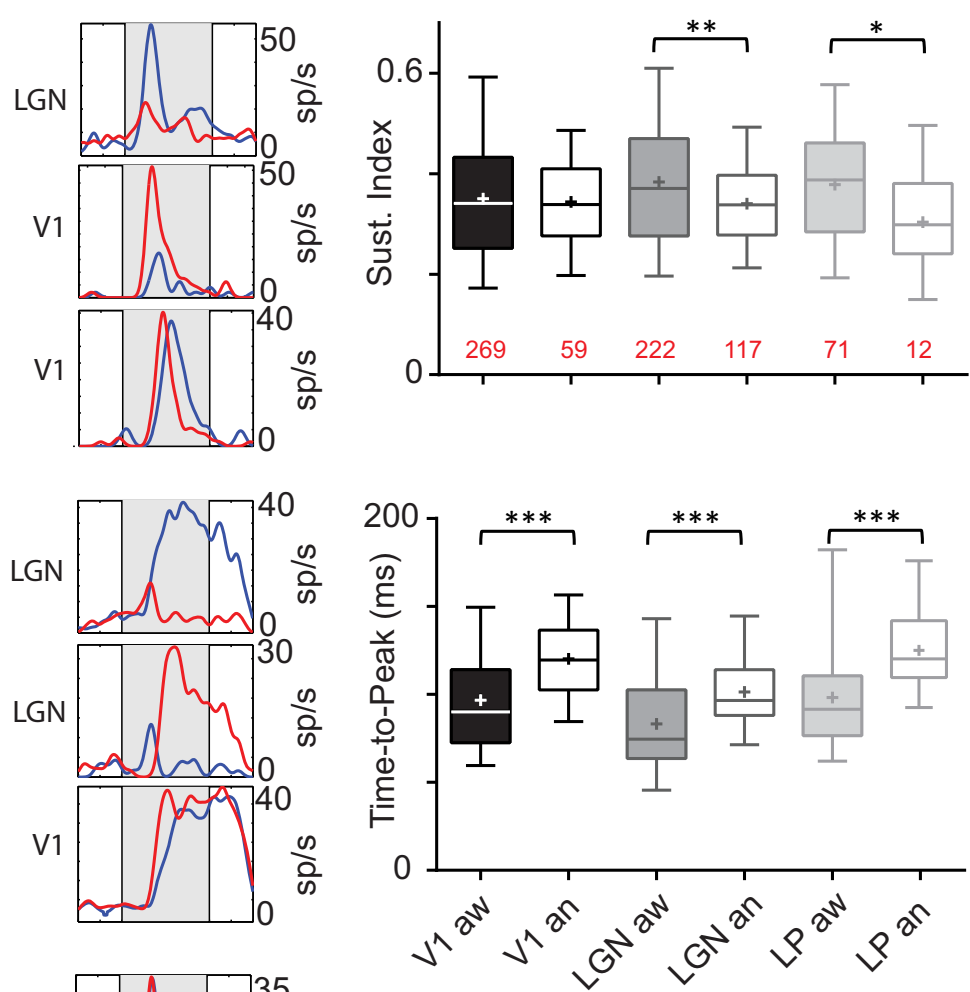
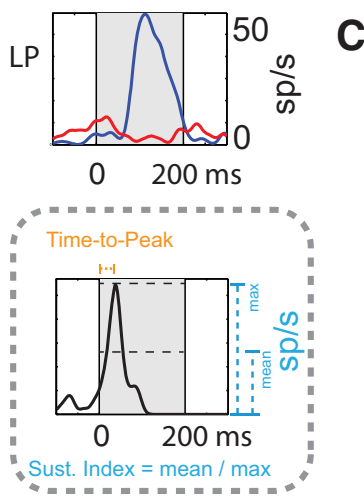

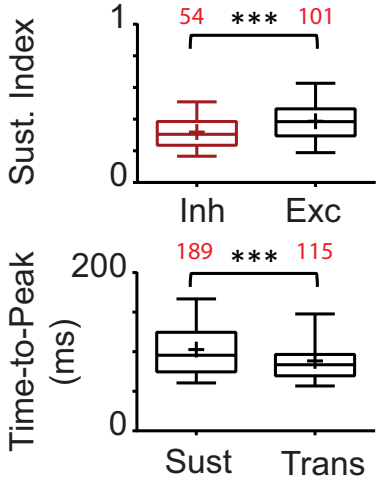

Figure 8. RF temporal characteristics. $\boldsymbol{A}$, PSTHs are shown and illustrate the diversity of response time course (transient or sustained) of ON (red) and OFF (blue) responses corresponding to V1, dLGN, and LP cells seen in Figure 7A (in a different order). Bottom panel, Schematic representation of how the time to peak and sustained index were measured. $\boldsymbol{B}$, Box plots represent medians as a bar, mean as a cross, and illustrate 5 th and 95 th percentiles. Mean of sustained index and time to peak values for each area and state. The sustained index is calculated as the ratio between the length of the response and that of the stimulus. Sustainedness is sensitive to state in $\mathrm{dLGN}$ (Mann-Whitney test, $p=0.005$ ) and LP (Mann-Whitney test, $p=0.037$ ). Time to peak is calculated from the PSTH as the time for the response to reach its maximum. Time to peak is extremely sensitive to anesthesia and is longer compared with responses in awake state for all areas. The number of subunits is in red. C, Top, Inhibitory cell sustained index is lower than excitatory neurons in the cortex $(0.317 \pm 0.018$ vs $0.390 \pm 0.01$; Mann-Whitney test, $p=$ 0.0009). Bottom, Cells with a sustained index $>0.3$ were classified as sustained, others as transient. The mean of time to peak for sustained (109.1 \pm 2.9$)$ and transient cells (90.2 \pm 3.1 , Mann-Whitney test, $p<0.0001)$. The number of subunits is in red. Putative excitatory and inhibitory cells are grouped together when not explicitly separated into two groups. ${ }^{*}, p<0.05 ;{ }^{* *}, p<$

shorter membrane time constant (Wang et al., 2014). In V1, conductance was not found to change in a population comparison of layer $2 / 3$ neurons in the awake and anesthetized states (Haider et al., 2013). This is compatible with our results, but it calls out for a similar study of dLGN neurons (Wang et al., 2014). 
Finally, we found that responses to flashed stimuli in V1 were equally sustained in the awake and anesthetized state, although a small (11\%) decrease was found for thalamic cells during anesthesia. This is in apparent contradiction to an intracellular study of layer $2 / 3$ neurons (Haider et al., 2013), but a comparison is difficult because the previous study used very brief stimuli (100 $\mathrm{ms}$ ) compared with ours (200-250 ms).

We found that cortical cells are more tuned to orientation in awake state, again consistent with a similar comparison in rabbit V1 between the alert and nonattentive states (Zhuang et al., 2014). They reported that orientation selectivity is enhanced in alertness by increasing visual response at the preferred stimulus and suppressing orthogonal directions (Carandini and Ferster, 2000; Isaacson and Scanziani, 2011). In awake or desynchronized state, inhibitory conductance is elevated and dominates (Haider et al., 2013; Wang et al., 2014). A spike thresholding or "iceberg effect," provoked by elevated inhibition, could account for these results (Jones and Palmer, 1987; Gardner et al., 1999). Similarly, in both dLGN and V1, we found an increase in the proportion of SC cells (Niell and Stryker, 2010; Piscopo et al., 2013) in V1 and dLGN.

\section{Properties immune to brain state}

Regardless of state and area, we found that neurons in early visual pathways in mice (dLGN, V1, and LP) respond to nearly identical ranges of peak spatial frequencies, consistent with past studies of dLGN and V1 in anesthetized animals (Grubb and Thompson, 2003; Niell and Stryker, 2008; Gao et al., 2010; Piscopo et al., 2013; Tang et al., 2016). The lack of effect of anesthesia on spatial frequency is supported by a study in attentive and nonattentive state in rabbits showing a multiplicative effect on spatial frequency tuning with no change in peak (Zhuang et al., 2014).

Similarly the spatial extent of the RF, as measured with sparse noise, was unchanged by anesthesia. This is in apparent contradiction with two studies of V1 (Haider et al., 2013; Vaiceliunaite et al., 2013), but the difference is likely due to the different stimuli used in the three studies. The extended 9 degree bars used by Haider et al. (2013) mapped the one-dimensional profile of the classical RF, or "center," which they defined as the central 27 degrees. Beyond this, they also characterized an excitatory "surround" response that was found to be weaker in the anesthetized state. These surround responses were not revealed with smaller spatial stimuli used in our study or in similar previous work (Niell and Stryker, 2008; Liu et al., 2009; Smith and Häusser, 2010; Lien and Scanziani, 2013), although we were able to study the central RF structure with greater precision. Similarly, Vaiceliunaite et al. (2013) performed a size tuning experiment, with bars of increasing width, to probe suppressive effects beyond the classical RF, again showing an increased inhibitory surround in awake animals.

Most electrophysiological studies in dLGN, LP, and V1 have been done under anesthesia. We used urethane, which is widely used in electrophysiology research, because it provides long periods of anesthesia with minimal physiological changes (Peng et al., 2011). Under urethane, we found that many visual properties do not change with state (e.g., orientation selectivity in $\mathrm{dLGN}$ and LP) and optimal spatial frequency, RF size, and subfield overlap in the three areas. Any of these modalities can be investigated during both anesthesia and the awake state with the similar outcomes. On the other hand, multiple temporal aspects of the response are changed under anesthesia, such as optimal temporal frequency, sustainedness of response, and time to peak response. These effects are likely due to decreased conductance resulting from a decreased inhibition in the anesthetized state (Haider et al., 2013), which likely also explains the smaller number of SC cells. Although we have concentrated on classical RF properties as revealed by simple stimuli, more complex aspects of visual response properties, such as the responses to natural scenes (Vinje and Gallant, 2000), are likely to be more profoundly affected by anesthesia.

\section{References}

Andermann ML, Kerlin AM, Roumis DK, Glickfeld LL, Reid RC (2011) Functional specialization of mouse higher visual cortical areas. Neuron 72:1025-1039. CrossRef Medline

Bezdudnaya T, Cano M, Bereshpolova Y, Stoelzel CR, Alonso JM, Swadlow HA (2006) Thalamic burst mode and inattention in the awake LGNd. Neuron 49:421-432. CrossRef Medline

Bonin V, Histed MH, Yurgenson S, Reid RC (2011) Local diversity and fine-scale organization of receptive fields in mouse visual cortex. J Neurosci 31:18506-18521. CrossRef Medline

Carandini M, Ferster D (2000) Membrane potential and firing rate in cat primary visual cortex. J Neurosci 20:470-484. Medline

Chalupa LM, Abramson BP (1989) Visual receptive fields in the striaterecipient zone of the lateral posterior-pulvinar complex. J Neurosci 9:347-357. Medline

Chalupa LM, Williams RW, Hughes MJ (1983) Visual response properties in the tectorecipient zone of the cat's lateral posterior-pulvinar complex: a comparison with the superior colliculus. J Neurosci 3:2587-2596. Medline

Chen Y, Anand S, Martinez-Conde S, Macknik SL, Bereshpolova Y, Swadlow HA, Alonso JM (2009) The linearity and selectivity of neuronal responses in awake visual cortex. J Vis 9:12 11-17. CrossRef Medline

Denman DJ, Contreras D (2015) Complex effects on in vivo visual responses by specific projections from mouse cortical layer 6 to dorsal lateral geniculate nucleus. J Neurosci 35:9265-9280. CrossRef Medline

Dräger UC (1975) Receptive fields of single cells and topography in mouse visual cortex. J Comp Neurol 160:269-290. CrossRef Medline

Enroth-Cugell C, Robson JG (1966) The contrast sensitivity of retinal ganglion cells of the cat. J Physiol 187:517-552. CrossRef Medline

Erisken S, Vaiceliunaite A, Jurjut O, Fiorini M, Katzner S, Busse L (2014) Effects of locomotion extend throughout the mouse early visual system. Curr Biol 24:2899-2907. CrossRef Medline

Funke K, Eysel UT (1992) EEG-dependent modulation of response dynamics of cat dLGN relay cells and the contribution of corticogeniculate feedback. Brain Res 573:217-227. CrossRef Medline

Gao E, DeAngelis GC, Burkhalter A (2010) Parallel input channels to mouse primary visual cortex. J Neurosci 30:5912-5926. CrossRef Medline

Gardner JL, Anzai A, Ohzawa I, Freeman RD (1999) Linear and nonlinear contributions to orientation tuning of simple cells in the cat's striate cortex. Vis Neurosci 16:1115-1121. CrossRef Medline

Glickfeld LL, Andermann ML, Bonin V, Reid RC (2013) Cortico-cortical projections in mouse visual cortex are functionally target specific. Nat Neurosci 16:219-226. CrossRef Medline

Grubb MS, Thompson ID (2003) Quantitative characterization of visual response properties in the mouse dorsal lateral geniculate nucleus. J Neurophysiol 90:3594-3607. CrossRef Medline

Haider B, Häusser M, Carandini M (2013) Inhibition dominates sensory responses in the awake cortex. Nature 493:97-100. CrossRef Medline

Harris KD, Henze DA, Csicsvari J, Hirase H, Buzsáki G (2000) Accuracy of tetrode spike separation as determined by simultaneous intracellular and extracellular measurements. J Neurophysiol 84:401-414. Medline

Hazan L, Zugaro M, Buzsáki G (2006) Klusters, NeuroScope, NDManager: a free software suite for neurophysiological data processing and visualization. J Neurosci Methods 155:207-216. CrossRef Medline

Hirsch JA, Gallagher CA, Alonso JM, Martinez LM (1998) Ascending projections of simple and complex cells in layer 6 of the cat striate cortex. J Neurosci 18:8086-8094. Medline

Hofer SB, Ko H, Pichler B, Vogelstein J, Ros H, Zeng H, Lein E, Lesica NA, Mrsic-Flogel TD (2011) Differential connectivity and response dynamics of excitatory and inhibitory neurons in visual cortex. Nat Neurosci 14:1045-1052. CrossRef Medline

Hubel DH (1958) Cortical unit responses to visual stimuli in nonanesthetized cats. Am J Ophthalmol 46:110-121; discussion 121-122. Medline 
Hubel DH, Wiesel TN (1959) Receptive fields of single neurones in the cat's striate cortex. J Physiol 148:574-591. CrossRef Medline

Hubel DH, Wiesel TN (1960) Receptive fields of optic nerve fibres in the spider monkey. J Physiol 154:572-580. CrossRef Medline

Hubel DH, Wiesel TN (1962) Receptive fields, binocular interaction and functional architecture in the cat's visual cortex. J Physiol 160:106-154. CrossRef Medline

Isaacson JS, Scanziani M (2011) How inhibition shapes cortical activity. Neuron 72:231-243. CrossRef Medline

Jasper HH, Ricci G, Doane B (1960) Microelectrode analysis of cortical cell discharge during avoidance conditioning in the monkey. Int J Electroencephalogr Clin Neurophysiol Suppl 137-156.

Jones JP, Palmer LA (1987) An evaluation of the two-dimensional Gabor filter model of simple receptive fields in cat striate cortex. J Neurophysiol 58: 1233-1258. Medline

Kerlin AM, Andermann ML, Berezovskii VK, Reid RC (2010) Broadly tuned response properties of diverse inhibitory neuron subtypes in mouse visual cortex. Neuron 67:858-871. CrossRef Medline

Kondo S, Ohki K (2016) Laminar differences in the orientation selectivity of geniculate afferents in mouse primary visual cortex. Nat Neurosci 19: 316-319. CrossRef Medline

Lein ES, Hawrylycz MJ, Ao N, Ayres M, Bensinger A, Bernard A, Boe AF, Boguski MS, Brockway KS, Byrnes EJ, Chen L, Chen L, Chen TM, Chin MC, Chong J, Crook BE, Czaplinska A, Dang CN, Datta S, Dee NR, et al. (2007) Genome-wide atlas of gene expression in the adult mouse brain. Nature 445:168-176. CrossRef Medline

Lien AD, Scanziani M (2013) Tuned thalamic excitation is amplified by visual cortical circuits. Nat Neurosci 16:1315-1323. CrossRef Medline

Liu BH, Li P, Li YT, Sun YJ, Yanagawa Y, Obata K, Zhang LI, Tao HW (2009) Visual receptive field structure of cortical inhibitory neurons revealed by two-photon imaging guided recording. J Neurosci 29:10520-10532. CrossRef Medline

Ma WP, Liu BH, Li YT, Huang ZJ, Zhang LI, Tao HW (2010) Visual representations by cortical somatostatin inhibitory neurons: selective but with weak and delayed responses. J Neurosci 30:14371-14379. CrossRef Medline

Mangini NJ, Pearlman AL (1980) Laminar distribution of receptive field properties in the primary visual cortex of the mouse. J Comp Neurol 193:203-222. CrossRef Medline

McCormick DA, Connors BW, Lighthall JW, Prince DA (1985) Comparative electrophysiology of pyramidal and sparsely spiny stellate neurons of the neocortex. J Neurophysiol 54:782-806. Medline

Mizuseki K, Sirota A, Pastalkova E, Buzsáki G (2009) Theta oscillations provide temporal windows for local circuit computation in the entorhinalhippocampal loop. Neuron 64:267-280. CrossRef Medline

Mountcastle VB, Talbot WH, Sakata H, Hyvärinen J (1969) Cortical neuronal mechanisms in flutter-vibration studied in unanesthetized monkeys: neuronal periodicity and frequency discrimination. J Neurophysiol 32: 452-484. Medline

Movshon JA, Thompson ID, Tolhurst DJ (1978a) Spatial summation in the receptive fields of simple cells in the cat's striate cortex. J Physiol 283:5377. CrossRef Medline

Movshon JA, Thompson ID, Tolhurst DJ (1978b) Receptive field organization of complex cells in the cat's striate cortex. J Physiol 283:79-99. CrossRef Medline

Niell CM, Stryker MP (2008) Highly selective receptive fields in mouse visual cortex. J Neurosci 28:7520-7536. CrossRef Medline

Niell CM, Stryker MP (2010) Modulation of visual responses by behavioral state in mouse visual cortex. Neuron 65:472-479. CrossRef Medline

Pape HC, McCormick DA (1995) Electrophysiological and pharmacological properties of interneurons in the cat dorsal lateral geniculate nucleus. Neuroscience 68:1105-1125. CrossRef Medline

Peirce JW (2007) PsychoPy-Psychophysics software in Python. J Neurosci Methods 162:8-13. CrossRef Medline
Peng QS, Zhou J, Shi XM, Hua GP, Hua TM (2011) Effects of urethane on the response properties of visual cortical neurons in young adult and old cats. Dongwuxue Yanjiu 32:337-342. CrossRef Medline

Piché M, Thomas S, Casanova C (2015) Spatiotemporal profiles of receptive fields of neurons in the lateral posterior nucleus of the cat LP-pulvinar complex. J Neurophysiol 114:2390-2403. CrossRef Medline

Piscopo DM, El-Danaf RN, Huberman AD, Niell CM (2013) Diverse visual features encoded in mouse lateral geniculate nucleus. J Neurosci 33:46424656. CrossRef Medline

Raiguel SE, Lagae L, Gulyàs B, Orban GA (1989) Response latencies of visual cells in macaque areas V1, V2 and V5. Brain Res 493:155-159. CrossRef Medline

Ringach DL, Shapley RM, Hawken MJ (2002) Orientation selectivity in macaque V1: diversity and laminar dependence. J Neurosci 22:5639-5651. Medline

Roth MM, Dahmen JC, Muir DR, Imhof F, Martini FJ, Hofer SB (2016) Thalamic nuclei convey diverse contextual information to layer 1 of visual cortex. Nat Neurosci 19:299-307. CrossRef Medline

Runyan CA, Sur M (2013) Response selectivity is correlated to dendritic structure in parvalbumin-expressing inhibitory neurons in visual cortex. J Neurosci 33:11724-11733. CrossRef Medline

Sawai H, Morigiwa K, Fukuda Y (1988) Effects of EEG synchronization on visual responses of the cat's geniculate relay cells: a comparison among $\mathrm{Y}$, X and W cells. Brain Res 455:394-400. CrossRef Medline

Shapley R, Hochstein S (1975) Visual spatial summation in two classes of geniculate cells. Nature 256:411-413. CrossRef Medline

Sirota A, Montgomery S, Fujisawa S, Isomura Y, Zugaro M, Buzsáki G (2008) Entrainment of neocortical neurons and gamma oscillations by the hippocampal theta rhythm. Neuron 60:683-697. CrossRef Medline

Skottun BC, De Valois RL, Grosof DH, Movshon JA, Albrecht DG, Bonds AB (1991) Classifying simple and complex cells on the basis of response modulation. Vision Res 31:1079-1086. CrossRef Medline

Smith SL, Häusser M (2010) Parallel processing of visual space by neighboring neurons in mouse visual cortex. Nat Neurosci 13:1144-1149. CrossRef Medline

Sohya K, Kameyama K, Yanagawa Y, Obata K, Tsumoto T (2007) GABAergic neurons are less selective to stimulus orientation than excitatory neurons in layer II/III of visual cortex, as revealed by in vivo functional $\mathrm{Ca}^{2+}$ imaging in transgenic mice. J Neurosci 27:2145-2149. CrossRef Medline

Stark E, Eichler R, Roux L, Fujisawa S, Rotstein HG, Buzsáki G (2013) Inhibition-induced theta resonance in cortical circuits. Neuron 80:12631276. CrossRef Medline

Swindale NV (1998) Orientation tuning curves: empirical description and estimation of parameters. Biol Cybern 78:45-56. CrossRef Medline

Tang J, Ardila Jimenez SC, Chakraborty S, Schultz SR (2016) Visual receptive field properties of neurons in the mouse lateral geniculate nucleus. PLoS One 11:e0146017. CrossRef Medline

Vaiceliunaite A, Erisken S, Franzen F, Katzner S, Busse L (2013) Spatial integration in mouse primary visual cortex. J Neurophysiol 110:964-972. CrossRef Medline

Vinje WE, Gallant JL (2000) Sparse coding and decorrelation in primary visual cortex during natural vision. Science 287:1273-1276.

Wang XD, Chen C, Zhang D, Yao H (2014) Cumulative latency advance underlies fast visual processing in desynchronized brain state. Proc Natl Acad Sci U S A 111:515-520. CrossRef Medline

Williams SR, Turner JP, Anderson CM, Crunelli V (1996) Electrophysiological and morphological properties of interneurones in the rat dorsal lateral geniculate nucleus in vitro. J Physiol 490:129-147. CrossRef Medline

Zhuang J, Bereshpolova Y, Stoelzel CR, Huff JM, Hei X, Alonso JM, Swadlow HA (2014) Brain state effects on layer 4 of the awake visual cortex. J Neurosci 34:3888-3900. CrossRef Medline 